\title{
BIRDSTRIKE ANALYSIS ON LEADING EDGE OF AN AIRCRAFT WING USING A SMOOTH PARTICLE HYDRODYNAMICS BIRD MODEL
}

\author{
A Thesis by \\ Vinayak Walvekar \\ Bachelor of Engineering, Visvesvaraya Technological University, 2007 \\ Submitted to the Department of Mechanical Engineering \\ and the faculty of the Graduate School of \\ Wichita State University \\ in partial fulfillment of \\ the requirements for the degree of \\ Master of Science
}

May 2010 
(C) Copyright 2010 by Vinayak Walvekar

All Rights Reserved 


\section{BIRDSTRIKE ANALYSIS ON LEADINGEDGE OF AN AIRCRAFT WING USING SMOOTH PARTICLE HYDRODYNAMICS BIRD MODEL}

The following faculty members have examined the final copy of this thesis for the form and content, and recommend that it be accepted in partial fulfillment of the requirement for the degree of Master of Science with a major in Mechanical Engineering.

Hamid Lankarani, Committee Chair

Ramazan Asmatulu, Committee Co-Chair

Bayram Yildirim, Committee Member 


\section{DEDICATION}

To my mom, my sisters, and my family and friends. 


\section{ACKNOWLEDGEMENTS}

I express my sincere gratitude to my advisor, Dr Hamid Lankarani, Professor of Mechanical Engineering, for his support, encouragement, and timely guidance throughout my graduation studies at Wichita State University. I express my gratitude to members of my committee, Dr Ramazan Asmatulu and Dr Bayram Yildirim for being on my committee and giving valuable suggestions.

I also thank Vikas Yadav, Senior Research Engineer at National Institute for Aviation Research (NIAR) for his invaluable advice, continuous guidance and support while working in the Computational Mechanics Laboratory at NIAR.

I thank NIAR for providing facilities required for conducting this research and my colleagues and friends who helped me throughout my research work.

Last, I thank my mom for her continuous and unconditional support throughout my studies. 


\begin{abstract}
Birdstrikes on aircraft pose a major threat to human life and there is a need to devolop structures which have high resistance towards these structures. According to the Federal Aviation Regulation (FAR 25.571) on Damage-tolerance and fatigue evaluation of structure (Amdt.25-96), an airplane must be capable of successfully completing the flight during which likely structural damage might occur as a result of impact with 4-lb bird at cruise velocity at sea level or 0.85 cruise velocity at 8000 feet.
\end{abstract}

The aim of the research is to develop a methodology which can be utilized to certify an aircraft for birdstrike using computational techniques since the physical testing of birdstrike is expensive, time consuming, cumbersome and for sanitary purpose.

The simulations are carried out in the LS Dyna, non-linear finite element analysis code, in which the bird is modeled using the Smooth Particle Hydrodynamics (SPH) technique. Initially to validate the bird model in the LS Dyna, the birdstrike is carried out on rigid and deformable plates. The results including displacement, Von-Mises stresses, forces, impulse, squash time and rise time are obtained from the simulation. Then the non-dimensional plots of force, impulse and rise time are plotted and compared with results from experimental test data.

The detailed CAD geometry of the leading edge is modeled in CATIA V5. Meshing, connections and material properties are then defined in the Altair Hypermesh 9.0. The validated SPH bird model is impacted at the leading edge. The results obtained from the simulation are compared with the data from the experiments, and the process is validated. The parametric studies are carried out by designing the leading edge for different values of nose radius and by 
assigning appropriate thickness values for leading edge components. Then the SPH bird model is impacted at varying impact velocites and results are compared with test data.

It is proposed that the results obtained from simulation can be utilized in the initial design stages as well as for certification of an aircraft for birdstrike requirements as per federal regulations. 


\section{TABLE OF CONTENTS}

Chapter $\quad$ Page

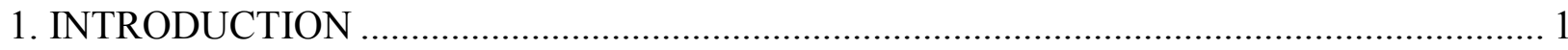

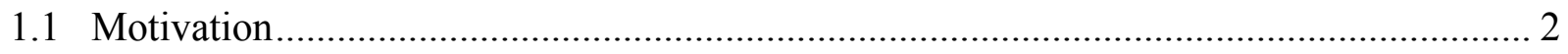

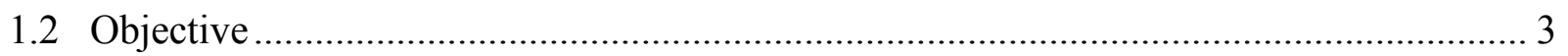

2. LITERATURE REVIEW ….................................................................................... 5

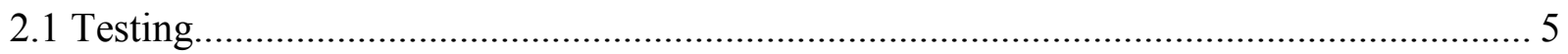

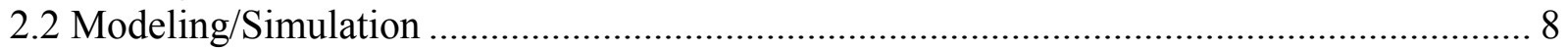

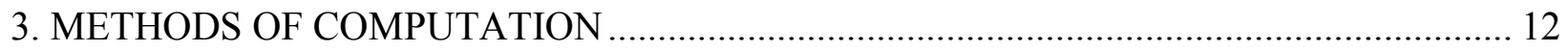

3.1 Lagrangian formulation ................................................................................... 12

3.2 Eulerian formulation ...................................................................................... 13

3.3 Arbitrary Lagrangian Eulerian (ALE) formulation................................................. 14

3.4 Smooth Particle Hydrodynamics (SPH) formulation ............................................. 15

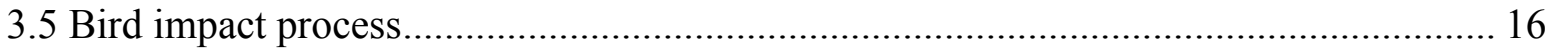

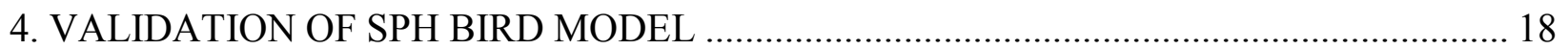

4.1 Validation of SPH bird by impacting with Al 7075 T6 target ...................................... 20

4.2 Validation of SPH bird by impacting with steel target .............................................. 23

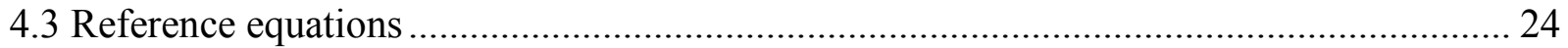

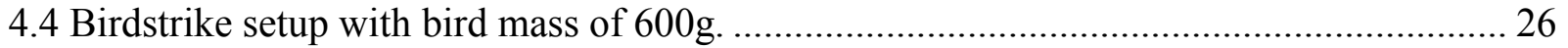

4.4.1 Calculation of non-dimensional impulse .......................................................... 27

4.4.2 Calculation of non-dimensional impact duration:............................................... 30

4.4.3 Calculation of non-dimensional peak force ......................................................... 32

4.4.4 Calculation of non-dimensional rise time ........................................................... 34

4.5 Birdstrike setup with bird mass of $1.81 \mathrm{Kg}$ with pitch distance $4 \mathrm{~mm}$ and $10 \mathrm{~mm}$............ 35

4.5.1 Calculation of non-dimensional impulse: ......................................................... 36

4.5.2 Calculation of non-dimensional impact duration:.............................................. 38

4.5.3 Calculation of non-dimensional peak force: .................................................... 40

4.5.4 Calculation of non-dimensional rise time: ..................................................... 42

5. BIRDSTRIKE ON LEADING EDGE OF AIRCRAFT WING ........................................ 44

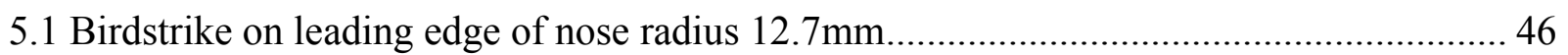

5.1.1 Birdstrike with impact velocity of 261 knots................................................. 47

5.1.2 Birdstrike with impact velocity of 427 knots.................................................. 49

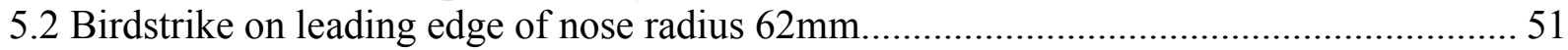

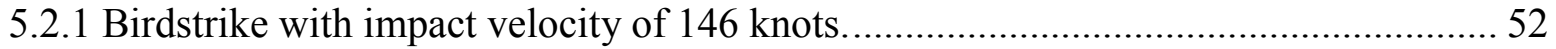

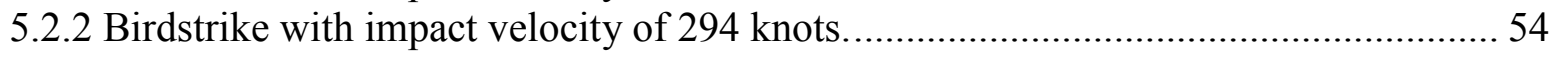

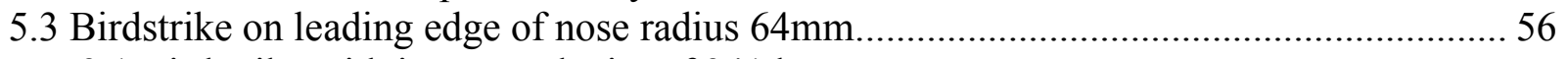

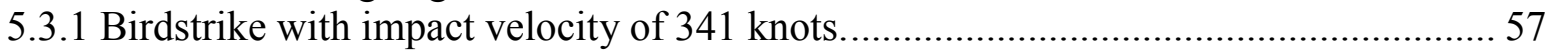




\section{TABLE OF CONTENTS (CONTINUED)}

Chapter

5.3.2 Birdstrike with impact velocity of 370 knots........................................................ 59

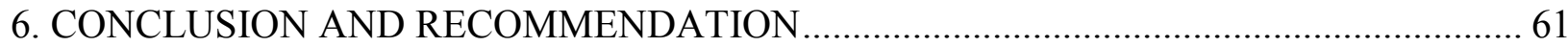

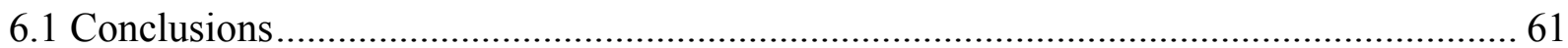

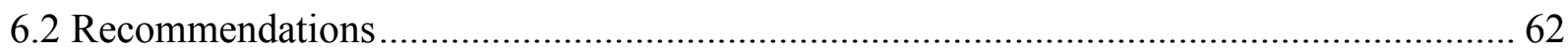

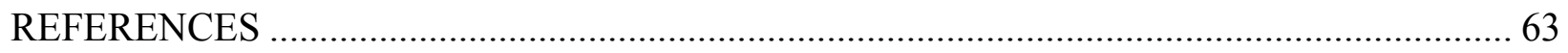

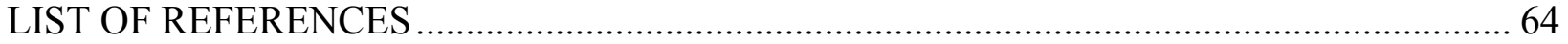




\section{LIST OF TABLES}

Table

Page

4.1 Equation of State for bird model ............................................................................ 20

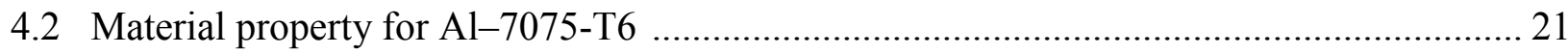

4.3 Comparison of testing results and simulations Lagrangian and SPH model ..................... 22

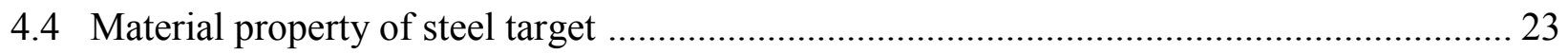

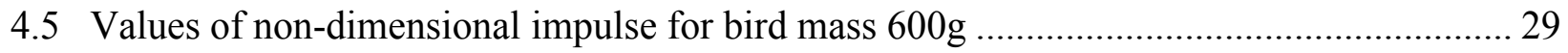

4.6 Values of non-dimensional impact duration for bird mass $600 \mathrm{~g}$................................... 31

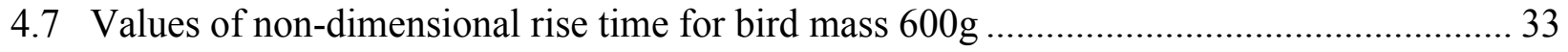

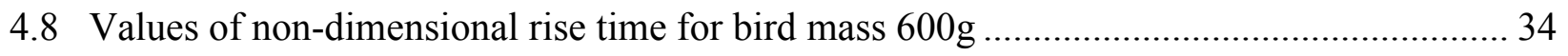

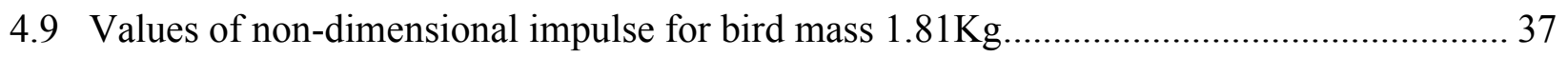

4.10 Values of non-dimensional impact duration for bird mass $1.81 \mathrm{Kg}$................................. 39

4.11 Values of non-dimensional impact duration for bird mass $1.81 \mathrm{Kg}$............................... 41

4.12 Values of non-dimensional rise time for bird mass $1.81 \mathrm{Kg}$....................................... 42

5.1 Thickness of leading edge parts for different nose radius .......................................... 44

5.2 Comparison of testing and simulation at impact velocity 261 knots ............................. 48

5.3 Comparison of testing and simulation at impact velocity 427 knots. ............................. 50

5.4 Comparison of testing and simulation at impact velocity 146 knots ............................... 53

5.5 Comparison of testing and simulation at impact velocity 146 knots .............................. 55

5.6 Comparison of testing and simulation at impact velocity 341 knots ...............................5 58

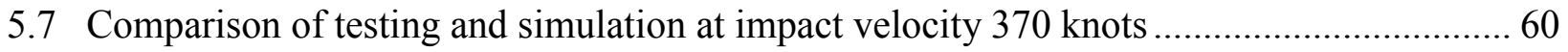




\section{LIST OF FIGURES}

Figure

Page

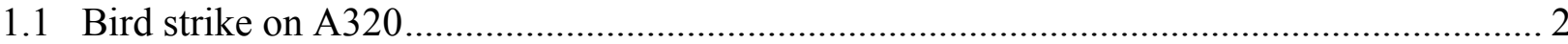

3.1 Lagrangian deformation for soft body impact simulation .......................................... 13

3.2 Simulation in Eulerian formulation ........................................................................ 14

3.3 Soft body impact in ALE formulation .................................................................. 15

3.4 Soft body impact in SPH formulation .................................................................... 16

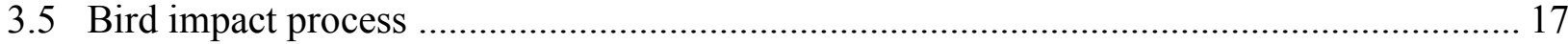

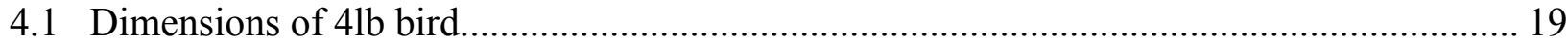

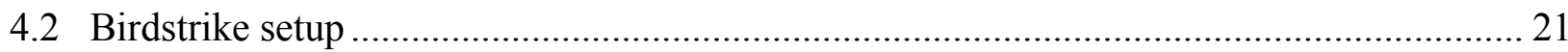

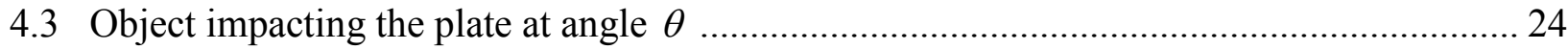

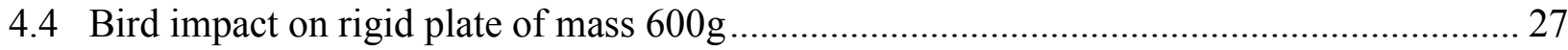

4.5 Force and Impulse Vs Time at V=192m/s, V=219m/s, V=249m/s, V=269m/s for bird mass

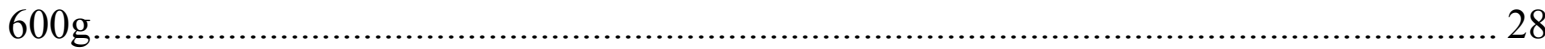

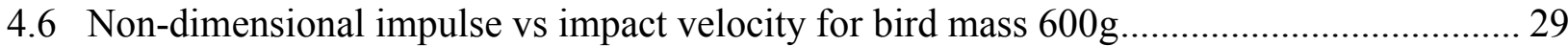

4.7 Non-dimensional impact duration vs impact velocity for bird mass $600 \mathrm{~g}$........................ 32

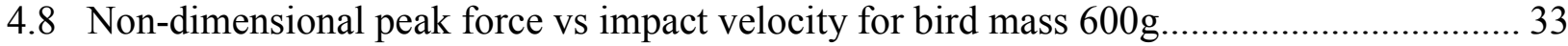

4.9 Non-dimensional rise time vs impact velocity for bird mass $600 \mathrm{~g}$............................... 35

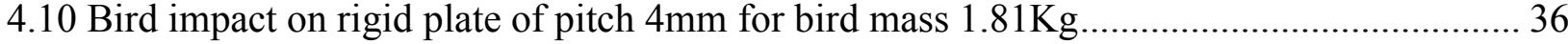

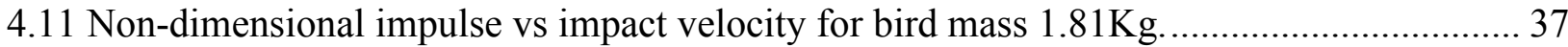

4.12 Non-dimensional impact duration vs impact velocity for bird mass $1.81 \mathrm{Kg}$................... 39

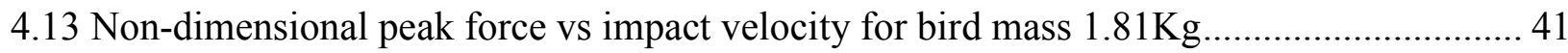

4.14 Non-dimensional rise time vs impact velocity for bird mass $1.81 \mathrm{Kg}$............................. 43

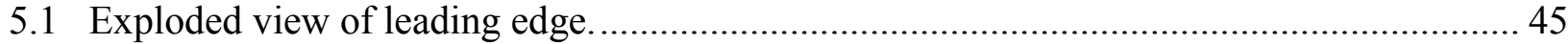

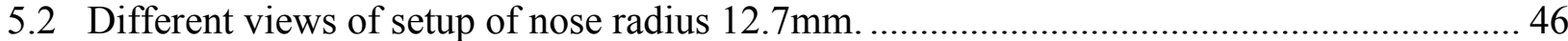

5.3 Frames at different instants of time for impact velocity 261 knots ............................... 47

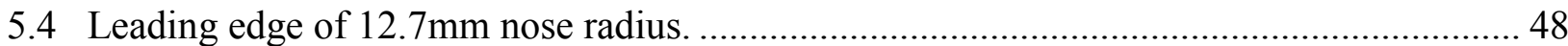

5.5 Frames at different instants of time for impact velocity 427 knots. ................................ 49

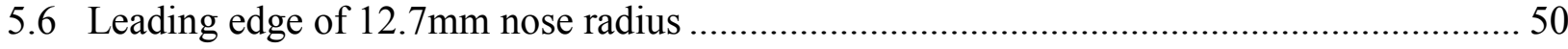

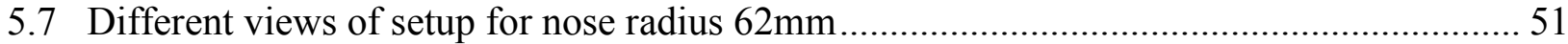

5.8 Frames at different instants of time at impact velocity 146 knots ................................. 52 


\section{LIST OF FIGURES (CONTINUED)}

Figure

Page

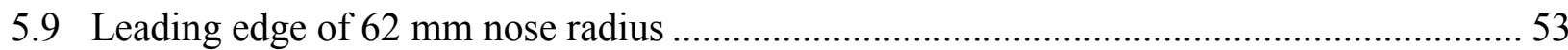

5.10 Frames at different instants of time at impact velocity 294 knots .................................... 54

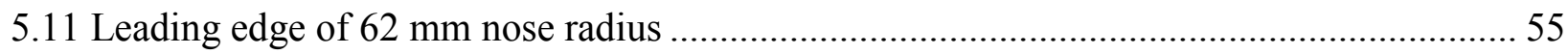

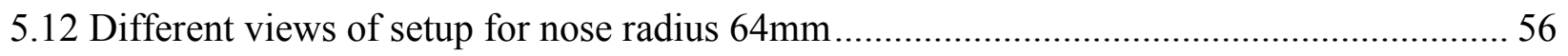

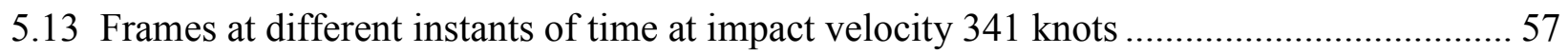

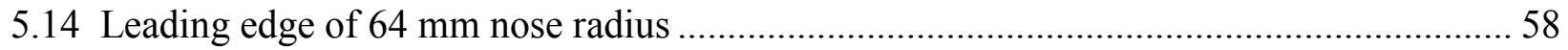

5.15 Frames at different instants of time at impact velocity of 370 knots .............................. 59

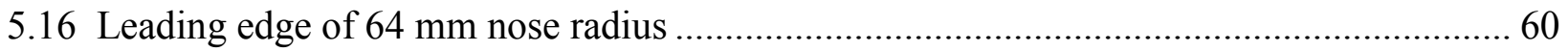




\section{LIST OF ABBREVIATIONS}

$\begin{array}{ll}\text { FAA } & \text { Federal Aviation Administration } \\ \text { SPH } & \text { Smooth Particle Hydrodynamics } \\ \text { ALE } & \text { Arbitrary Lagrangian Eulerian } \\ \text { CAD } & \text { Computer Aided Design } \\ \text { CAE } & \text { Computer Aided Engineering } \\ \text { FE } & \text { Finite Element } \\ \text { FEA } & \text { Finite Element Analysis } \\ \text { FAR } & \text { Federal Aviation Regulation } \\ \text { CFR } & \text { Code of Federal Regulation. } \\ V_{c} & \text { Cruise Velocity } \\ \text { EOS } & \text { Equation of State. }\end{array}$




\section{CHAPTER 1}

\section{INTRODUCTION}

The collision between the aircraft and bird is inevitable and the damage caused due to these collisions is catastrophic. As a result efforts are being taken to make structures which have high resistance towards birdstrikes. Bird and other wildlife strikes on aircraft cause a damage of $\$ 600$ million [25] for US Aviation Industry and \$3 billion annual loss for worldwide aviation sector. It is estimated that more than 30,000 birdstrikes occur annually to civilian aircrafts.

For FAA certification purpose, an aircraft must be able to complete the flight when it is impacted by $4 \mathrm{lb}$ bird during which likely structural damage might occur. The birds [25] that are generally involved in these strikes are Waterfowl (31\%), Gulls (25\%), Raptors (18\%), Pigeons/Doves (7\%) represented $81 \%$ of the reported birdstrikes causing damage to US civil aircraft between 1990-2008 and about 1500 Canadian Geese strikes were also reported between this period. From 1990-2009, 381 different species of birds were involved in strikes with US civil aircrafts that were reported by FAA. In Table 1.1, the mass of bird for certification requirements on different parts of leading edge is specified with section numbers of Federal Aviation Regulation.

Table 1.1: Bird strike requirements [7]

\begin{tabular}{|c|c|c|}
\hline Part & Bird Mass & FAR \\
\hline Leading edge wing & $4 \mathrm{lb}$ & 25.571 \\
\hline $\begin{array}{c}\text { Leading edge } \\
\text { empennage }\end{array}$ & $8 \mathrm{lb}$ & 25.631 \\
\hline Windshield & $4 \mathrm{lb}$ & 25.775 \\
\hline Engine & $4 \mathrm{lb}$ & 25.571 \\
\hline
\end{tabular}


The bird strikes on aircraft usually occur during take-off or landing. Birds are attracted to airports for various reasons like the large open grassed areas provide perfect feeding, nesting and resting areas for many breeds of birds. There are various methods adopted for bird control and management like reducing the amount of water lying on airport grounds and using hand held laser devices for deterring bird from staying on airport grounds. Also remote bird sensors are widely used for detection and avoidance of birds during night operations.

One of the examples of catastrophe caused by bird strike is the bird impact on aircraft engine of US Airways, Airbus A320 in January 2009 as shown in figure 1.1. The aircraft ditched into Hudson river after experiencing loss of both the turbines after impacting with flock of geese.

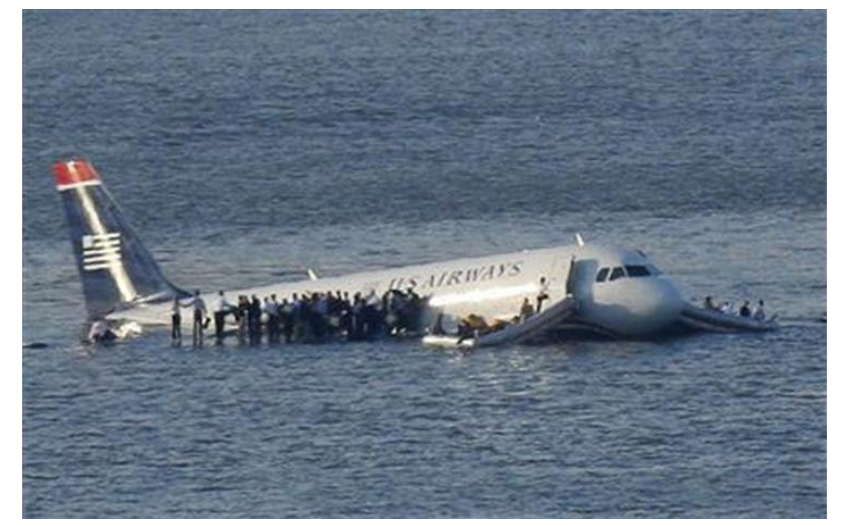

Figure 1.1 Bird strike on A320 [11].

\subsection{Motivation}

The loss to human life and aircraft industry has been enormous due to birdstrikes. An aircraft as a whole is a huge structure and birdstrike can occur on any part of the aircraft. Thus practical testing for birdstrike on aircraft structure becomes very complex and expensive affair. 
Hence the efficient way to certify an aircraft as per federal standards is by using analysis tools which gives accurate results, standardizes the procedure and saves time and money.

\subsection{Objective}

The objective of the research is to devolop a methodology to certify an aircraft for birdstrike by analysis technique in the LS Dyna, non-linear finite element code is used for analysis tool. The following steps were followed to devolop a methodology for certification.

To validate the SPH bird model by carrying out impact on deformable and rigid plates and plotting the simulation results with the test data. The bird is modeled in LS Prepost using Smooth Particle Hydrodynamics technique with pitch distance of $4 \mathrm{~mm}$. Then the validation of bird model is carried out by impacting the bird on rigid and deformable targets and comparing the simulation results with test data from literature. The results obtained from simulation are displacement, Von-Mises stresses, forces, impulse, rise time and squash time. Then the nondimensional values of force, impulse, rise and squash time are calculated by carrying certain mathematical operations and results are plotted against the test data and compared.

The effect of pitch distance on birdstrike analysis is observed by varying the pitch distance from $4 \mathrm{~mm}$ to $10 \mathrm{~mm}$ and plotting the results. It is concluded that pitch distance does not have much effect on birdstrike analysis.

Modeling and Analysis of Leading Edge:

The geometry of leading edge is modeled in CATIA V5 by obtaining the dimensions from Royal Aircraft Establishment report [20]. The meshing, connections and material properties are defined in Altair Hypermesh 9.0. The connections are defined using spotwelds and beam 
elements. Then the analysis is carried out in the LS Dyna by using the validated SPH bird model and impacting on leading edge. The results obtained from simulation are compared with results from test data and the process is validated.

The parametric study of leading edge is carried out by varying its nose radius and thickness of main skin, leading edge skin, main rib and leading edge rib. The bird is impacted with different velocities and results are tabulated and compared. 


\section{CHAPTER 2}

\section{LITERATURE REVIEW}

In order to make this review available as a quick reference of literature for this research, the documents are organized into groups depending on their main theme. For instance, document about testing are in one group and simulation/modeling techniques are in another group.

\subsection{Testing}

This section collects documents that concentrate in birdstrike testing only. The list of documents contains a brief description or summary of each document"s contents.

In Air Force Flight Dynamics Laboratory Technical Report [1], the document describes the experimental and analytical investigation of bird impact loading with a bird of different masses from 60 grams to 4 kilograms. The bird impact is observed when the plate is held straight and when the plate is held oblique, at an angle $\left(90^{\circ}, 45^{\circ}\right.$ and $\left.25^{\circ}\right)$. There is no simulation carried out of the bird impact and the experimental results are validated using analytical calculations. The bird is impacted with velocities ranging from $50 \mathrm{~m} / \mathrm{s}$ to $300 \mathrm{~m} / \mathrm{s}$ ( 100 knots to $585 \mathrm{knots}$ ).It describes the way the bird is launched at different velocities and the equipment used to launch. It discusses about Hopkinson bar technique for determining force time histories and also explains the different pressures exerted by the bird during impact. The initial pressure generated is hugoniot pressure and the second phase involves decay of very high shock pressures. The third phase is the phase in which bird material flows steadily toward the target and equivalent jet flow is established. The last phase involves termination of force and pressures to zero. 
In Dept. Mechanical Engineering Institute for Soldier Nanotechnologies and Army research laboratory conference Paper [4] focuses on the behavior of polymers to impact loads, in particular with Polycarbonate (PC) and Polymethylmethacarbonate (PMMC). A sample of $6.35 \mathrm{~mm}$ thick PC plate is impacted with a round nose projectile and simulations are carried out without any detail on the modeling techniques. The combination of PC and PMMC is used and the results are observed. Not much information about the modeling performed, it explains mainly the testing done and the design of impact resistant polymers, no data about the bird weight and test speeds.

In Farnborough aerospace centre, Hampshire, UK, and department of applied mechanics University of Gent, Belgium, Technical Paper [5] gives a general description of the validation of bird models for Birdstrike analysis and shows some experimental results. No detail on testing or modeling methodology and suggests that experimental data from bird splitting tests is necessary to validate gelatin and real birds for simulation. The paper provides information on bird density and about its geometrical properties like length, diameter

Birdstrike Avoidance Team, Central Science Laboratory, Technical paper [6] provides the formulae for calculating a typical bird properties based on collected biometric data of real birds. These properties are density and body diameter for any specified bird mass. It shows the properties of an arbitrarily chosen $2.5 \mathrm{lb}$ bird using equations. The density of a $2.5 \mathrm{lb}$ projectile would be $0.95 \mathrm{~g} / \mathrm{cm}^{3}$ with a diameter of $8.1 \mathrm{~cm}$. The density of chicken would be $1.04 \mathrm{~g} / \mathrm{cm}^{3}$ and the density of a $2.5 \mathrm{lb}$ Herring Gull is $0.89 \mathrm{~g} / \mathrm{cm}^{3}$. Toughness or resistance to splitting of the bird is also mentioned but not considered in this study although it is said that it will be in future work. No artificial bird manufacturing process is presented in this work and also there is no testing 
validation done.

Social studies of Science, Vol 37, No 1, 7-26 [7], the paper gives information about the advantages and disadvantages of using real birds for representativeness or gelatin packs for reproducibility and explains the FAA requirements for engine birdstrike, listing the required bird masses, number of birds or volleys, and impact speed. A single $4 \mathrm{lb}$ bird or an $8 \mathrm{lb}$ for very large engines, volley of 8 birds of $1.5 \mathrm{lbs}$, and a volley of 16 birds of $3 \mathrm{oz}$., all of them at 200 knots ans states that density of an artificial bird is the average density of a real bird.

ASTM International F-330-89 [8], the document provides information on standard method for birdstrike tests on aerospace transparent enclosures. The testing apparatus consists of a gun, pressure tank, release mechanism, barrel, sabot stripper and velocity measurement system. The velocity measurement system must be accurate and repeatable; it should not be triggered by small stray objects that travel with the projectile. The bird combined with the packaging forms the projectile .The standard weight used in the test is $4-1 \mathrm{~b}(1.81 \mathrm{~kg})$ and the bird container is used to prevent the bird from damage before impacting the specimen. The weight of the container shall not exceed $10 \%$ of the total projectile weight.

U.S. Department of Transportation [9](Federal Aviation Administration), the report describes the deformation and failure behavior of Ti-6Al-4V and 2024-T3 Aluminum. The Split Hopkinson pressure bar technique is used to obtain high strain rates and large strains and the results of experimental work are used to define a new set of material constants like Cowper Symonds failure factors for the strength component of the Johnson-Cook model for Ti-6Al-4V and 2024-T3 Al. The major concern with the Johnson-Cook material is its ability to accurately represent the stress-strain rate response at strain rates greater than $10^{3}-10^{4} \mathrm{~s}^{-1}$ 
University of Dayton Research Institute and Air Force Materials Laboratory, Technical Report [10] where the purpose of this study has been to experimentally determine the pressuretime variations generated by small birds impacting a flat rigid plate in an effort to characterize the loading of real aircraft components by bird impacts. Pressure data are given for two bird weights $(70 \mathrm{~g}$ and $125 \mathrm{~g}$ ) with velocities ranging from $60 \mathrm{~m} / \mathrm{s}$ to $350 \mathrm{~m} / \mathrm{s}$. The objective of this program is to characterize the loading behavior of the birds at impact, to characterize the response of real aircraft components to the impact of birds and to develop design methods and criteria and explains the technique for launching small birds at velocities up to $350 \mathrm{~m} / \mathrm{s}$ which is used to obtain reliable bird velocity measurements and also the technique to measure the pressure on a rigid plate.

\subsection{Modeling/Simulation}

This section collects documents that concentrate in birdstrike simulation only. The list of documents contains a brief description or summary of each document's contents.

Department of Aeronautics Imperial College London Conference Paper [11], where the bird is modeled with $90 \%$ by volume of water and $10 \%$ with air. The length to breadth ratio is 2 and it is modeled as cylindrical body with spherical end caps. The bird is modeled first with Lagrangian element formulation and afterwards with Smooth Particle Hydrodynamics (SPH) and the document is concerned primarily with in-plane failure in woven glass composite, with seven damage variables introduced to model the observed fiber and matrix damage. In the second case the bird is modeled as SPH and results are analyzed. It is observed that SPH bird modeling technique appears to be a robust approach. The simulation results are compared to experimental results and no details are given about the bird modeling to be able to use as guideline. It 
concentrates on the modeling of the glass composite failure. The bird is fired at two different impact velocities of 287 and 476 knots and its effect on the ply is observed.

Federal Aviation Administration Report DOT/FAA/AR-03/57 [12], the document develops failure strain parameters for titanium and aluminum which are then used for simulating impact damage .Johnson-Cook material model is used in the simulation and the results are compared with tests data. The failure strain parameters for titanium are obtained from Hopkinson bar test data correlation, and the aluminum parameters are obtained from simulation of one-thirdscale ballistic limit test results correlations. The failure strain parameters are validated by comparing the failure pattern of titanium and aluminum plates due to fragment impact tests. Not much detail is given about the modeling; it concentrates on the development of failure strains from test data for simulation.

CAD-FEM GmbH Grafing/Munich, and Dept. of Aeronautical and Mechanical Engineering [13] describes the analysis of a rigid pole impact with a composite horizontal tail as well as a birdstrike onto a metallic horizontal tail leading edge. The bird is modeled using Lagrangian and ALE formulations and the paper describes in good detail the modeling methodology of the bird by the two different formulations. The Lagrangian FE model for bird is delivered by Airbus UK and it is modeled as cylindrical body with semi circular ends. The total length of the model is $0.228 \mathrm{~m}$ and it end radius is $0.057 \mathrm{~m}$.the density is given as $934 \mathrm{~kg} / \mathrm{m}^{3}$ Dept. Aerospace Engineering, Politecnico di Milano Italy, conference paper [14], describes in general terms the analysis of a birdstrike on a turbofan engine. The bird is modeled with different formulations, and advantages and disadvantages are discussed for each formulation approach. The bird has a dimension of $20 \mathrm{~cm}$ in length and $10 \mathrm{~cm}$ in diameter and for testing purpose 4-lb chickens were launched using air gun at an angle of 30 degrees with initial velocity of $265 \mathrm{knots}$. 
It concludes that SPH is the best method for modeling the bird.

Phoenix analysis and design technologies, Inc., conference paper [16] ,describes a generic simulation of a birdstrike on an engine fan using Arbitrary-Lagrangian-Eulerian formulation. It mentions the type of cards that are used for defining materials, hourglass, damping, and ALE but it is very general. No test data is presented or mentioned and no information is given about modeling of the bird or its properties and gives some general idea on how long it takes to run these types of models and the outputs produced.

National aerospace laboratory, technical report [17], mainly deals with birdstrike on horizontal leading edge of an airplane. There are three alternative designs for horizontal leading edge, which are manufactured and tested, and simulation is carried out in pam-crash. Design requirement for HTP is that the load on the leading edge must not exceed $200 \mathrm{KN}$ to avoid excessive loads on stabilizer."Tensor Skin" concept is used for energy absorption of transversely loaded structure. Three different designs for leading edge with varying layup are subjected to tests. Birdstrike tests are carried out with 4-lb bird on these specimens at impact velocities of $80-100 \mathrm{~m} / \mathrm{s}$.

Models and methods for birdstrike load predictions [21], describes about different projectile shapes and equation of state for bird models are investigated. The bird is modeled with homogenous and heterogeneous composition using SPH method. Also the effect of porosity in bird composition is discussed. There is no practical testing carried out and results of the simulations are compared with data from Wilbeck [1] and results are validated. The birdstrike event is carried out at different impact angles and shock pressure and steady state pressure are compared with test data. 
University of Puerto Rico [18], describes birdstrike event against a fan-blades. The fanblades are composed of both flat and tapered sections and hence birdstrike against flat and tapered plate is carried out using Lagrangian, SPH and ALE formulations. The length to diameter ratio $(\mathrm{L} / \mathrm{D})$ is 2.03 and a density of $912.61 \mathrm{~kg} / \mathrm{m}^{3}$, cut-off pressure of $0.09974 \mathrm{MPa}$, and an impact velocity of $198 \mathrm{~m} / \mathrm{s}$ on rigid flat plate and $477.4 \mathrm{~m} / \mathrm{s}$ on tapered plate. The material used for rigid flat plate target is 4340 Steel and for tapered plate is Titanium 6-4 plate and is observed that the computational time required for SPH formulation is higher than ALE formulation. The birdstrike analysis can be carried out using Lagrangian, ALE and SPH formulation for the bird but ALE and SPH give better results. 


\section{CHAPTER 3 \\ METHODS OF COMPUTATION}

In LS Dyna, analysis can be carried out using different formulations like Lagrangian, Eulerian, Arbitrary Lagrangian Eulerian (ALE) and Smooth Particle Hydrodynamics (SPH) technique.

\subsection{Lagrangian formulation}

In Lagrangian formulation the mesh nodes are connected to material by certain imaginary points called Integration points. The mesh follows the material i.e. one material per element during the entire simulation. This formulation is generally used for solid materials. In Lagrangian approach the history dependent variables can be easily tracked. The disadvantage of this formulation is the need of remeshing because of the mesh deformations. Since mesh follows the material, if there is large material deformation the mesh quality deteriorates causing which might lead to inaccurate results and error termination of analysis.

The deformation of Lagrangian mesh [18] is shown in figure 3.1 at different instants of time and we can observe that mesh which follows the material and might result in inaccurate results in case of large deformations 

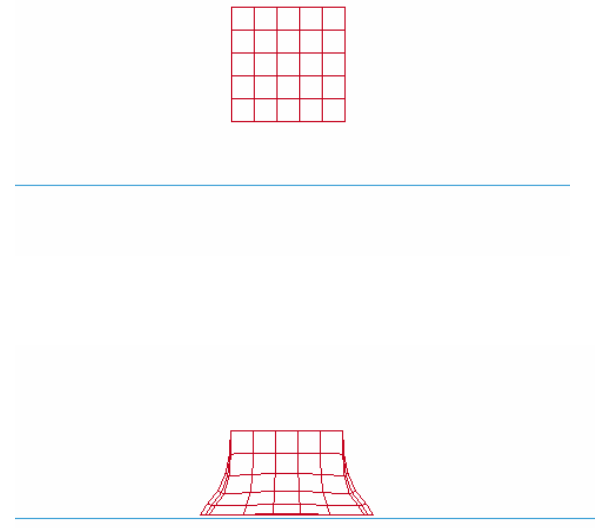

Figure 3.1 Lagrangian deformation for soft body impact simulation [18]

\subsection{Eulerian formulation}

In Eulerian formulation the reference mesh is fixed in space and material is moving or convecting through the elements. As shown in figure 3.2, in Eulerian formulation, the material and the mesh are updated as in Lagrangian formulation but the reference mesh is moved back to its original position. The element history variables are mapped on to the reference mesh. To the user, the mesh never moves but material convects through the elements.

This formulation is mostly applied to fluid applications. Since the mesh is fixed there is no possibility of mesh distortion which is a major advantage when compared with Lagrangian formulation. But Eulerian formulation requires more computations than Lagrangian, which 
results in longer simulation time. Also it is difficult to track material interfaces and history of material variables.

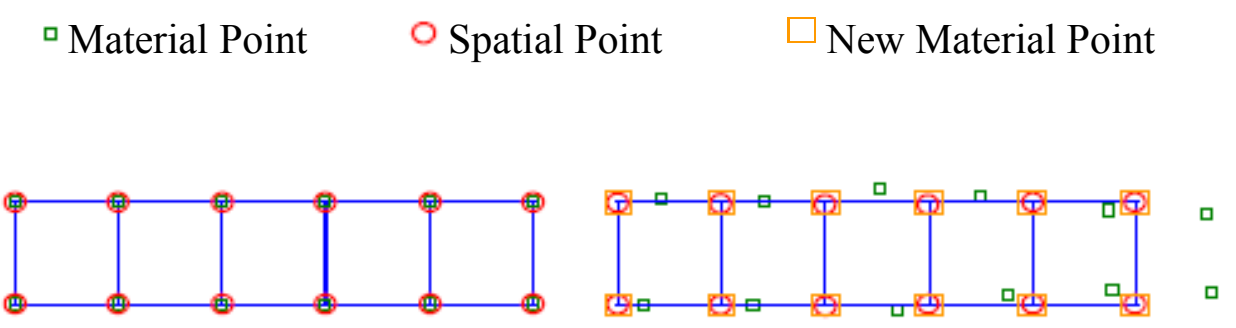
a) At time $t_{1}$
b) At time $t_{2}$

Figure 3.2 Simulation in Eulerian formulation [21]

\subsection{Arbitrary Lagrangian Eulerian (ALE) formulation}

In ALE formulations there are two meshes, reference mesh and material mesh. The reference is moving and material mesh is moving based on some "arbitrarily" user defined condition. In ALE, the material and mesh are updated based on Lagrangian formulation. The mesh is then moved based on some arbitrary condition and element history variables are mapped on to updated arbitrary mesh. To the user the material moves arbitrarily.

The main objective of ALE method is to maximize the benefits of Lagrangian and Eulerian formulations while minimizing their disadvantages. ALE formulation consists of a Lagrangian time step followed by "advection" step. In advection step the position of the nodes are moved by small fraction of characteristic lengths of surrounding elements.

In figure 3.3 soft body impact simulation using ALE formulation is shown at different instants of time. ALE formulation can be considered similar to Lagrangian formulation and manual rezoning needs to be performed if entirely new mesh is required to continue the 
calculation. But the accuracy of ALE calculation is superior to manually rezoned calculation because the algorithm for ALE calculation is of second order accuracy and for manual rezoning it is of first order accurate.

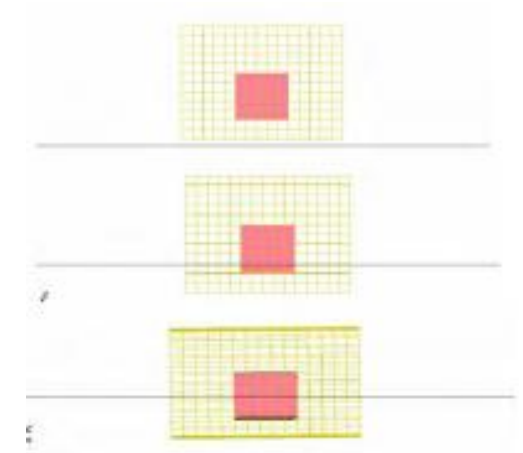

Figure 3.3 Soft body impact in ALE formulation [18]

\subsection{Smooth Particle Hydrodynamics (SPH) formulation}

SPH is mesh free method and there is no physical contact between the particles. It can handle very deformations compared to ALE formulation. The computations in SPH are carried out by sorting technique and in the simulations the particle sorting is carried out after each cycle to determine the number of neighbors for each particle. The spatial distance also known as smoothing length varies in order to keep the same number of neighbors during simulation. In compression the smoothing length gets smaller and during tension it gets bigger. In this technique each particle has a mass assigned to it.

In figure 3.4 the soft body impact simulation [18] using SPH formulation is shown at different instants of time. 


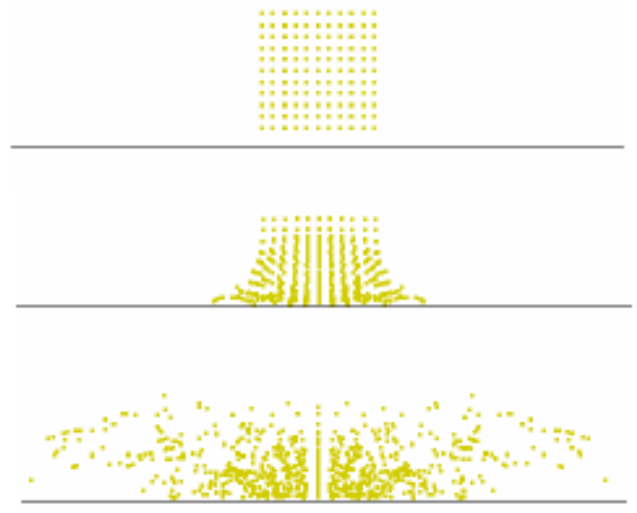

Figure 3.4 Soft body impact in SPH formulation [18]

\subsection{Bird impact process}

The bird impact process can be considered as a hydrodynamic impact, since at very high velocity the bird model behaves similar to fluid.

The bird impact process can be divided into four stages [2]:

- Initial impact phase,

- Shock propagation,

- State of steady flow,

- Pressure decay phase.
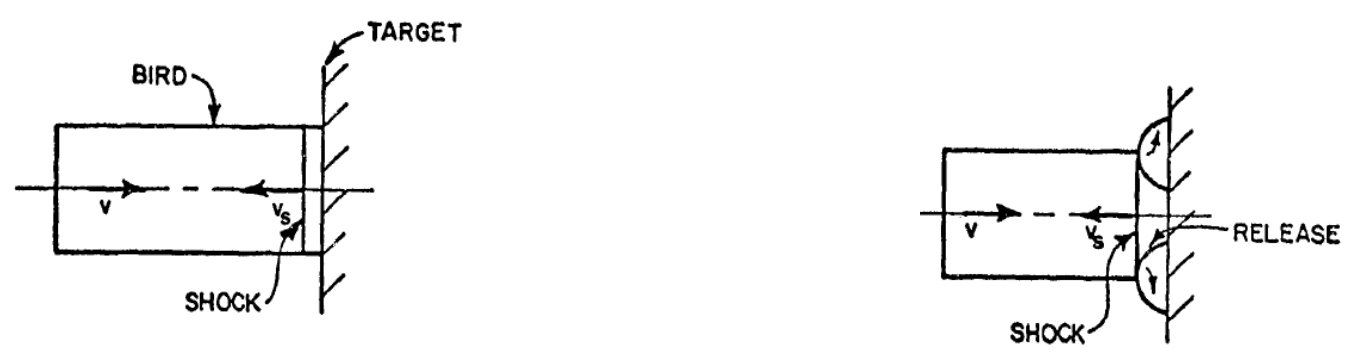

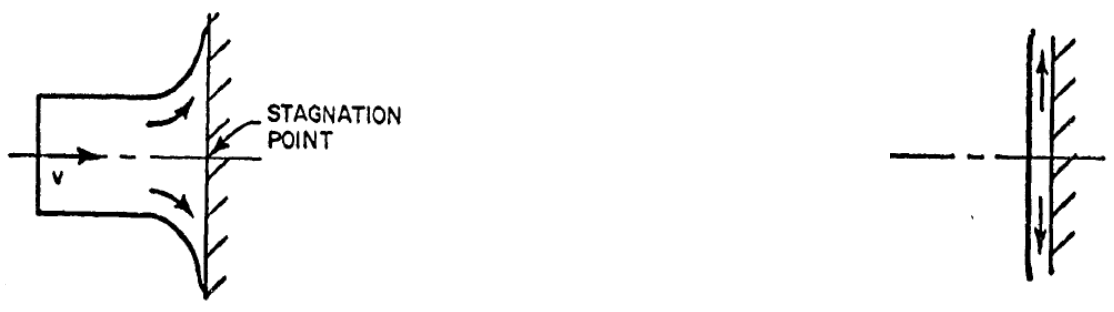

Figure 3.5 Bird impact process [2]

At the initial impact phase the particles at front end are brought to rest instantaneously and the shock wave propagates through the projectile. As the shock wave propagates it brings the material behind the shock to rest. The pressure in the shock compressed region is referred as Hugoniot pressure.

Although the magnitude of the pressure is very high it lasts only for few micro seconds. There exists a pressure gradient at the edge of the projectile which makes the particle to flow steadily and in the outward direction. After several reflections of release waves, a steady flow condition is established. As the impact continues there will be decay process where the pressure reduces to zero and is the termination phase. 


\section{CHAPTER 4}

\section{VALIDATION OF SPH BIRD MODEL}

The SPH bird model needs to be validated before it can be used for leading edge analysis. Thus SPH bird model is impacted on aluminum and steel plate target and results are compared to validate the bird model.

The modeling of SPH bird model is carried out in LS Prepost. A cylindrical model with hemispherical ends is modeled and parameters like pitch distance and density are specified.

The bird characteristics like diameter, cylindrical length, density are obtained by certain empirical formulae from literature [24]

Bird mass $=4-1 \mathrm{~b}=1.81 \mathrm{Kg}$

$\operatorname{Density}($ plucked $)=959-63 \cdot \log _{10}($ Mass $)=942.7 \mathrm{~kg} / \mathrm{m}^{3}$

Diameter $=0.0804 \cdot$ Mass $^{0.335}=0.098 m$

For a cylindrical model bird with hemispherical ends:

CylinderLength $=4 \cdot\left(\frac{\text { Mass }}{\pi \cdot{\text { Density } \cdot \text { Diameter }^{2}}_{\text {Diameter }}}\right)=0.189 \mathrm{~m}$

TotalLength $=0.189+0.098=0.287 \mathrm{~m}$ 


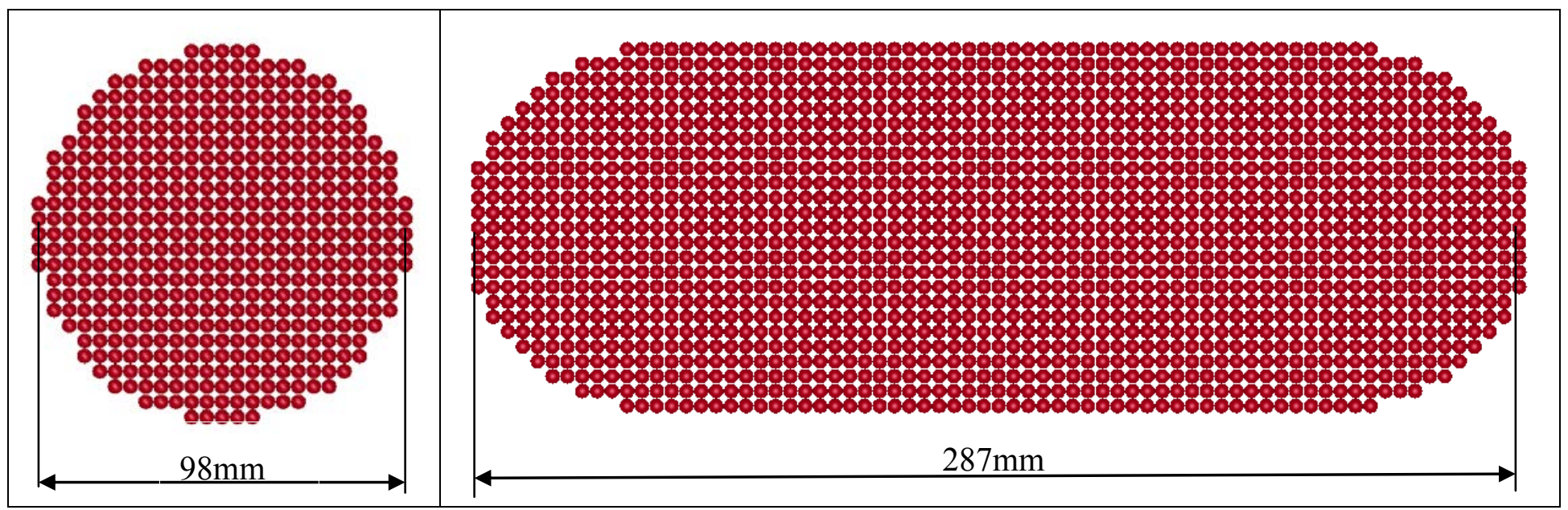

Figure 4.1 Dimensions of 4lb bird

In LS Dyna deck the bird is defined by MAT_NULL card where the parameters are substituted and Equation of State (EOS) is specified in part card.

A thermodynamic state of homogenous material which does not undergo any phase changes or chemical reactions may be defined by two state variables and this relation is called is called EOS. The equation used for this material model is EOS_TABULATED which defines pressure $\mathrm{P}$ as follows,

$$
\mathrm{P}=\mathrm{C}\left(\varepsilon_{V}\right)+\gamma \mathrm{T}\left(\varepsilon_{V}\right) \mathrm{E}
$$

Where $\mathrm{C}$ represents the function or constant array and $\mathrm{T}$, the temperature which depends on volumetric strain. $\varepsilon_{V}$ is natural logarithm of the relative volume $\mathrm{V}$ and $\mathrm{E}$ is the internal energy. But for high impact process like birdstrike, the temperature $\mathrm{T}$ does not play very major role and hence it is negligible. Thus the term $\gamma \mathrm{T}\left(\varepsilon_{V}\right) \mathrm{E}$ becomes zero. The effective EOS becomes,

$$
\mathrm{P}=\mathrm{C}\left(\varepsilon_{V}\right)
$$


EOS_TABULATED card is used in LS Dyna where volumetric strain and tabulated points for function C are substituted [18]. This EOS is defined for SPH bird model with composition of $90 \%$ water and $10 \%$ air. The values of $\varepsilon_{V}$ and $\mathrm{C}$ are determined by carrying out certain calculations. These values are used to compute pressure in the bird.

Table 4.1 Equation of State for bird model [18]

\begin{tabular}{|c|c|}
\hline $\boldsymbol{\varepsilon}_{\boldsymbol{V}}$ & $\mathbf{C}$ \\
\hline 1 & -5000 \\
\hline 0 & 0 \\
\hline-0.0953 & 294 \\
\hline-0.1044 & 1470 \\
\hline-0.1124 & 2940 \\
\hline-0.1178 & 4410 \\
\hline-0.1258 & 5880 \\
\hline-0.131 & 7350 \\
\hline-0.1484 & 14700 \\
\hline-0.2327 & 73500 \\
\hline
\end{tabular}

\subsection{Validation of SPH bird by impacting with Al 7075 T6 target}

To validate the SPH bird model, it is impacted on Al 7075 T6 plate and simulation results are compared with literature [15]. In this report actual physical testing of birdstrike are carried out at Cessna and simulation is carried out using lagrangian bird model.

The birdstrike set up consisted of an Al 7075 T6 plate with length of $914.4 \mathrm{~mm}$ and breadth of $609.5 \mathrm{~mm}$. The SPH bird is impacted at the centre of the plate. The set up is as shown in figure 4.2. In figure 4.2(a) and 4.2(b) the front view and profile view of the set-up is shown. 


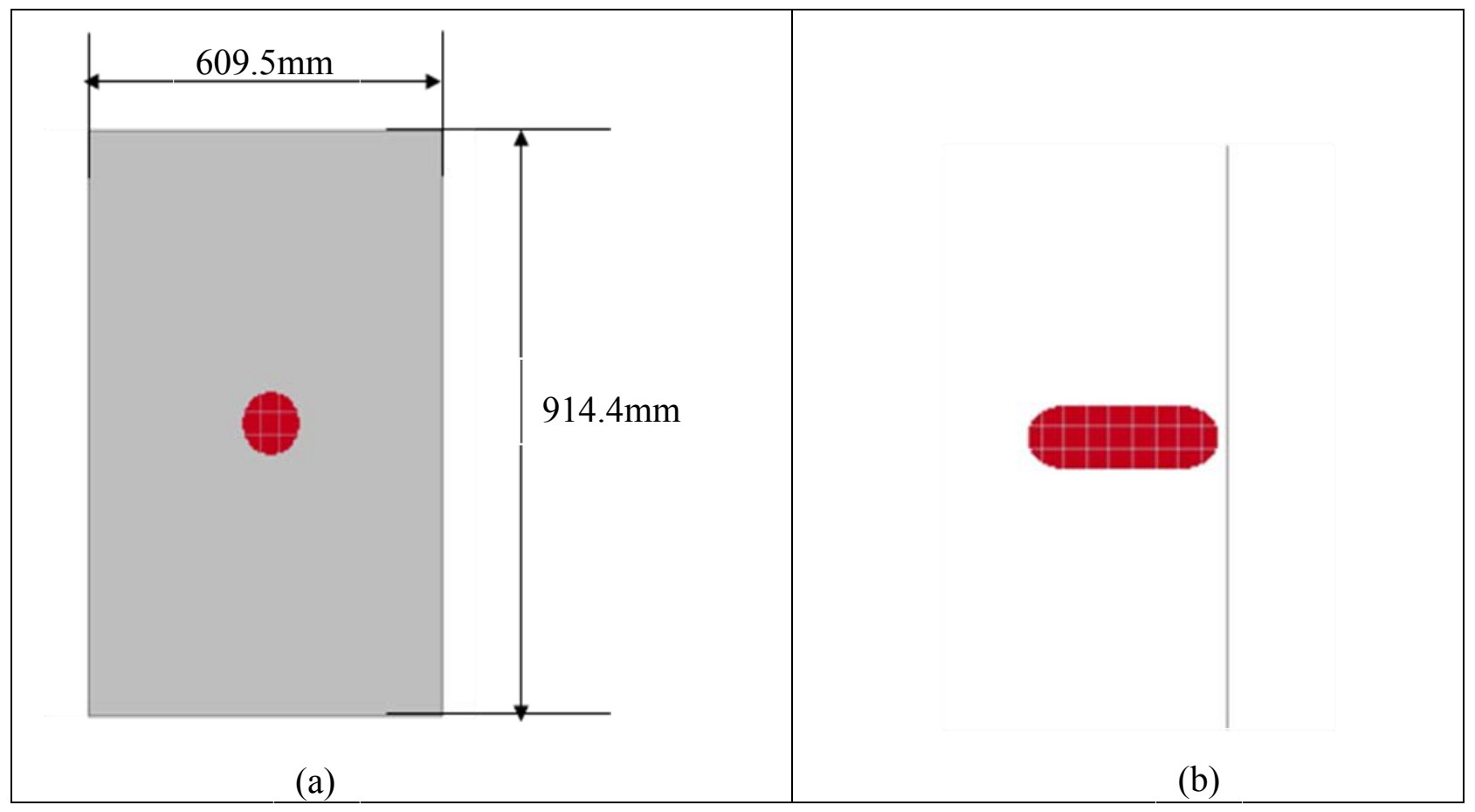

Figure 4.2 Birdstrike setup

The aluminum plate is constrained in $\mathrm{X}, \mathrm{Y}$ and $\mathrm{Z}$ directions. The thickness of the aluminum plate $0.25 ", 0.16$ " and 0.1 inch and impacted with 265 knots, 269 knots and 275 knots respectively.

The material property is assigned for the plate is mentioned in table 4.2.

Table4.2 Material property for Al-7075-T6 [15]

\begin{tabular}{|c|c|}
\hline Density & $2.81 \mathrm{E}-9$ tonne $/ \mathrm{mm}^{3}$ \\
\hline Ultimate strength & $570 \mathrm{MPa}$ \\
\hline Yield strength & $505 \mathrm{MPa}$ \\
\hline Modulus of Elasticity & $72000 \mathrm{MPa}$ \\
\hline
\end{tabular}


In the LS Dyna deck the material properties for the aluminum plate is defined through MAT_PLASTIC_KINEMATIC card where the values are substituted in the card. The thickness of the plate is specified using SECTION_SHELL card.

The SPH bird model is made as node set and velocity is assigned to the node set using INITIAL_VELOCITY card in dyna deck.

The analysis is carried out for $5 \mathrm{~ms}$ and SPH simulation results are compared with Cessna test results and Lagrangian simulation results.

The simulation results like displacement or deformation and Von-Mises stresses are obtained from Altair Hyperview 9.0 and are tabulated in table 4.3.

Table 4.3 Comparison of testing results and simulations Lagrangian and SPH model

\begin{tabular}{|c|c|c|c|c|}
\hline \multicolumn{2}{|c|}{ Plate Thickness } & \multirow{2}{*}{$\begin{array}{c}\text { Test Results } \\
1.0 \text { inch }\end{array}$} & \multirow{2}{*}{$\begin{array}{c}\begin{array}{c}\text { Simulation Results } \\
\text { with Lagrangian } \\
\text { Model }\end{array} \\
1.3 \text { inch }\end{array}$} & \multirow{2}{*}{$\begin{array}{l}\text { Simulation results } \\
\text { with SPH model } \\
1.2 \mathrm{inch}\end{array}$} \\
\hline $0.25 \mathrm{inch}$ & Deformation & & & \\
\hline & $\begin{array}{c}\text { Max Von Mises } \\
\text { Stress }\end{array}$ & NA & $71.05 \mathrm{Kpsi}$ & 73.24Kpsi \\
\hline \multirow[t]{2}{*}{0.16 inch } & Deformation & 1.5 inch & 1.3 inch & 1.8 inch \\
\hline & $\begin{array}{c}\text { Max Von Mises } \\
\text { Stress }\end{array}$ & NA & 73.2Kpsi & 73.1Kpsi \\
\hline $0.10 \mathrm{inch}$ & Deformation & $\begin{array}{l}\text { Material } \\
\text { Failure }\end{array}$ & Material Failure & Material Failure \\
\hline
\end{tabular}


The results show that variation in test results and SPH simulation results show a variation of around $12 \%$ which is acceptable.

\subsection{Validation of SPH bird by impacting with steel target}

The SPH bird model is impacted on the steel plate in which the corner nodes are constrained in $\mathrm{X}, \mathrm{Y}$ and $\mathrm{Z}$ directions. The birdstrike set up is shown in figure 4.3. The bird is impacted at different impact velocites and forces are obtained from load cell. The material properties for the plate is assigned using MAT_PLASTIC_KINEMATIC card in dyna deck. The thickness of the plate is assigned using SECTION_SHELL card.

Table 4.4: Material property of steel target [26,27]

\begin{tabular}{|c|c|}
\hline Density & $7.85 \mathrm{E}-9$ tonne $/ \mathrm{mm}^{3}$ \\
\hline Tangent modulus & $431 \mathrm{MPa}$ \\
\hline Yield strength & $460 \mathrm{MPa}$ \\
\hline Modulus of elasticity & $205000 \mathrm{MPa}$ \\
\hline
\end{tabular}

The simulation is divided into three phases:

In phase I, bird of mass $600 \mathrm{~g}$ with pitch distance of $4 \mathrm{~mm}$ is impacted on steel plate at an angle of 90 degree.

In phase II, bird of mass $1.81 \mathrm{Kg}$ (4-lb) with pitch distance of $4 \mathrm{~mm}$ is impacted on steel plate at an angle of 90 degree. 
In phase III, bird of mass $1.81 \mathrm{Kg}(4-\mathrm{lb})$ with pitch distance of $10 \mathrm{~mm}$ is impacted on steel plate at an angle of 90 degree.

The parameters that are compared with test data [2] are non-dimensional impulse, nondimensional impact duration, non-dimensional peak force and non-dimensional rise time. These values are obtained by carrying out certain mathematical operations.

\subsection{Reference equations}

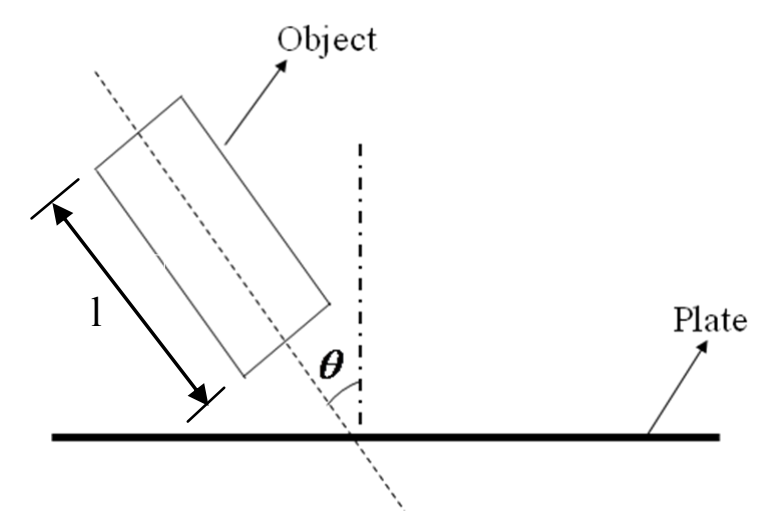

Figure 4.3 Object impacting the plate at angle $\theta$

In order to determine certain reference equations, let us consider an object of mass ,me with length ,le impacting the plate with velocity , $\mathrm{V}^{\mathrm{ee}}$ at an angle $\theta$.

In case of bird strike the impulse is the product of mass, velocity with Sine of the impact angle. The final velocity will be zero in this process.

$$
\text { Impulse, } I=m v \operatorname{Sin} \theta
$$

Where

$$
m=\text { Mass of the bird }
$$


$v=$ Impact velocity

$\theta=$ Impact angle - Angle between trajectory and surface of the target

The squash time for the bird strike process is the time required for the entire bird to disintegrate. It is obtained by dividing length of the specimen with its impact velocity.

$$
\text { Squash Time, } \quad T_{s}=l / v
$$

Where

$$
\begin{aligned}
& l=\text { Length of the bird } \\
& v=\text { Velocity during impact }
\end{aligned}
$$

The effective length of the bird is obtained by the sum of length of the bird and product of diameter with tangent of the impact angle.

Effective length of the bird, $\quad l_{e f f}=l+d \operatorname{Tan} \theta$

Where

$$
\begin{aligned}
& l=\text { Length of the bird } \\
& d=\text { Diameter of the bird }
\end{aligned}
$$

The average impact force is calculated by using mass, velocity, impact angle and effective length of the bird as shown in equation 4.4. 


$$
\text { Average impact force, } \quad F_{a v g}=\frac{m v^{2} \operatorname{Sin} \theta}{l_{e f f}}
$$

Where

$$
\begin{aligned}
& m=\text { Mass of the bird } \\
& v=\text { Impact velocity } \\
& \theta=\text { Impact angle }- \text { Angle between trajectory and surface of the target } \\
& l_{\text {eff }}=\text { Effective length of the bird }
\end{aligned}
$$

\subsection{Birdstrike setup with bird mass of $600 \mathrm{~g}$.}

The bird is impacted on steel plate at different impact velocities of $192 \mathrm{~m} / \mathrm{s}, 219 \mathrm{~m} / \mathrm{s}$, $249 \mathrm{~m} / \mathrm{s}$ and $269 \mathrm{~m} / \mathrm{s}$ with the plate at an angle of 90 degree and is compared with the data from the literature [2] and the results are plotted. Figure 4.3 shows different views of the birdstrike set up where (a) shows lateral view of the set up while (b) shows front view. 


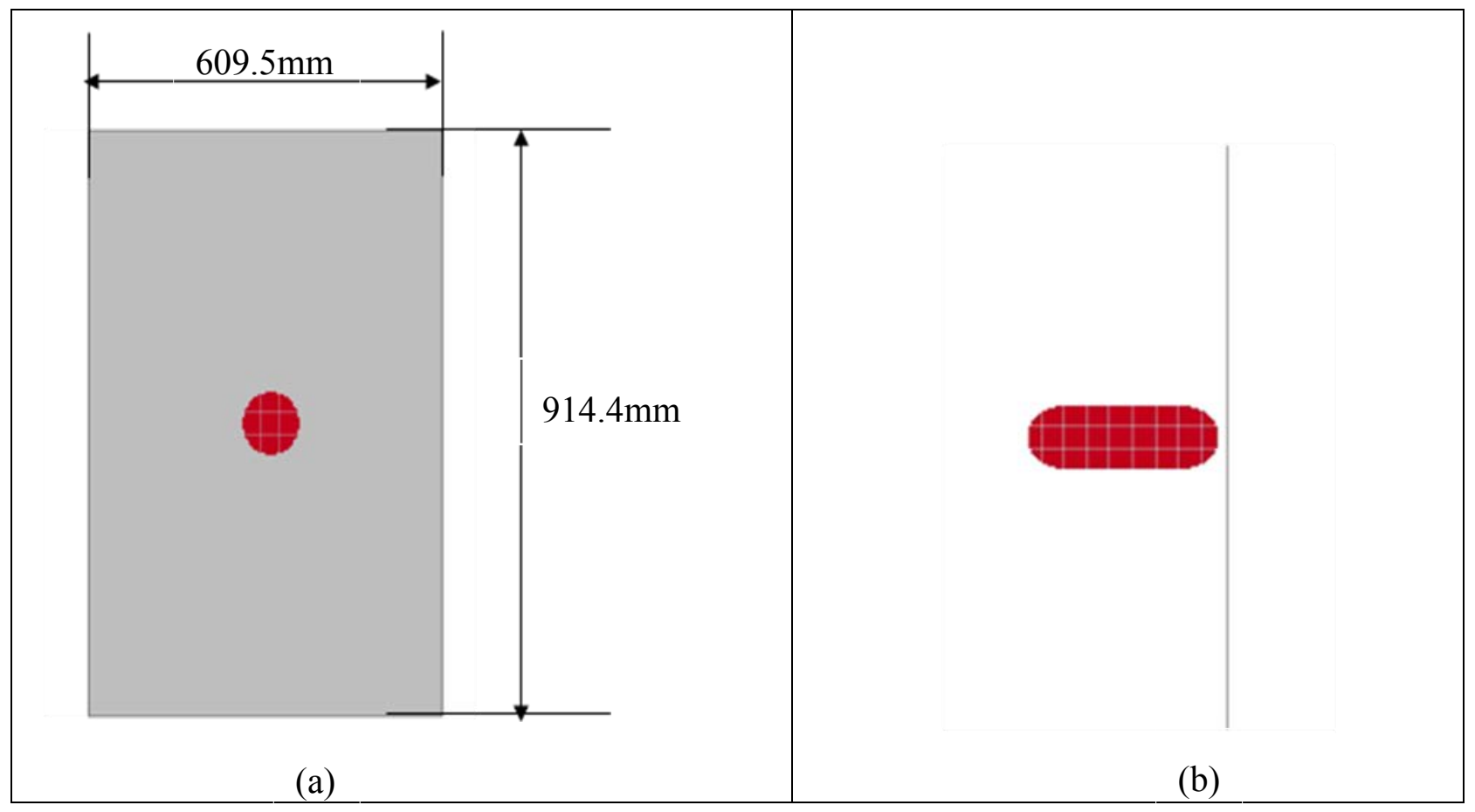

Figure 4.4 Bird impact on rigid plate of mass $600 \mathrm{~g}$

\subsubsection{Calculation of non-dimensional impulse}

In figure 4.5, force vs time and impulse vs time plots are shown. Figure 4.5 (a) is the plot for impact velocity of $192 \mathrm{~m} / \mathrm{s}$ and figure 4.5 (b), 4.5 (c), 4.5 (d) are for $219 \mathrm{~m} / \mathrm{s}, 249 \mathrm{~m} / \mathrm{s}$ and $269 \mathrm{~m} / \mathrm{s}$ respectively.

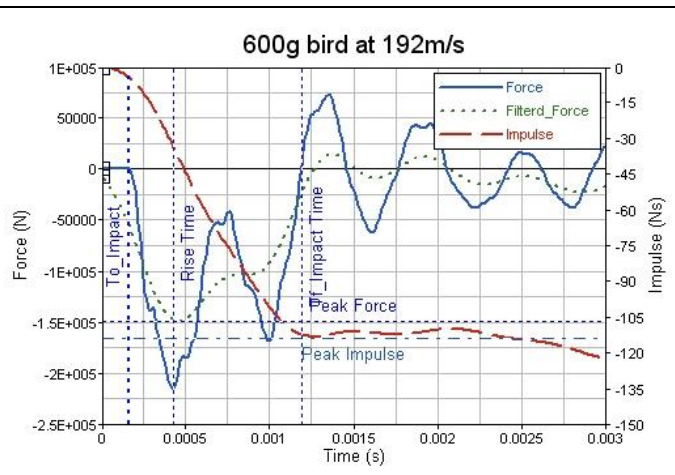

(a)

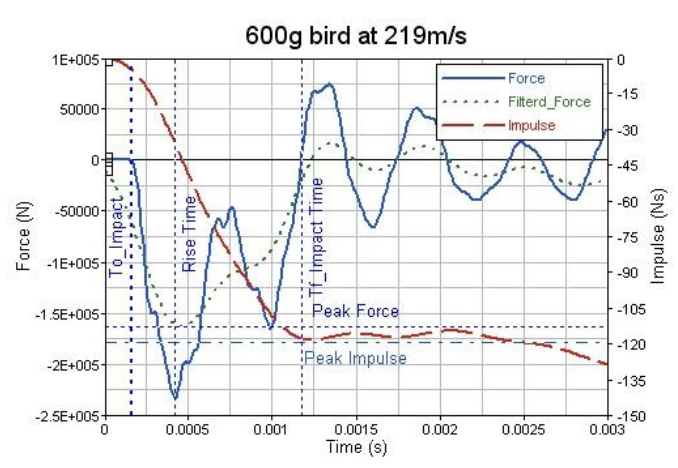

(b) 


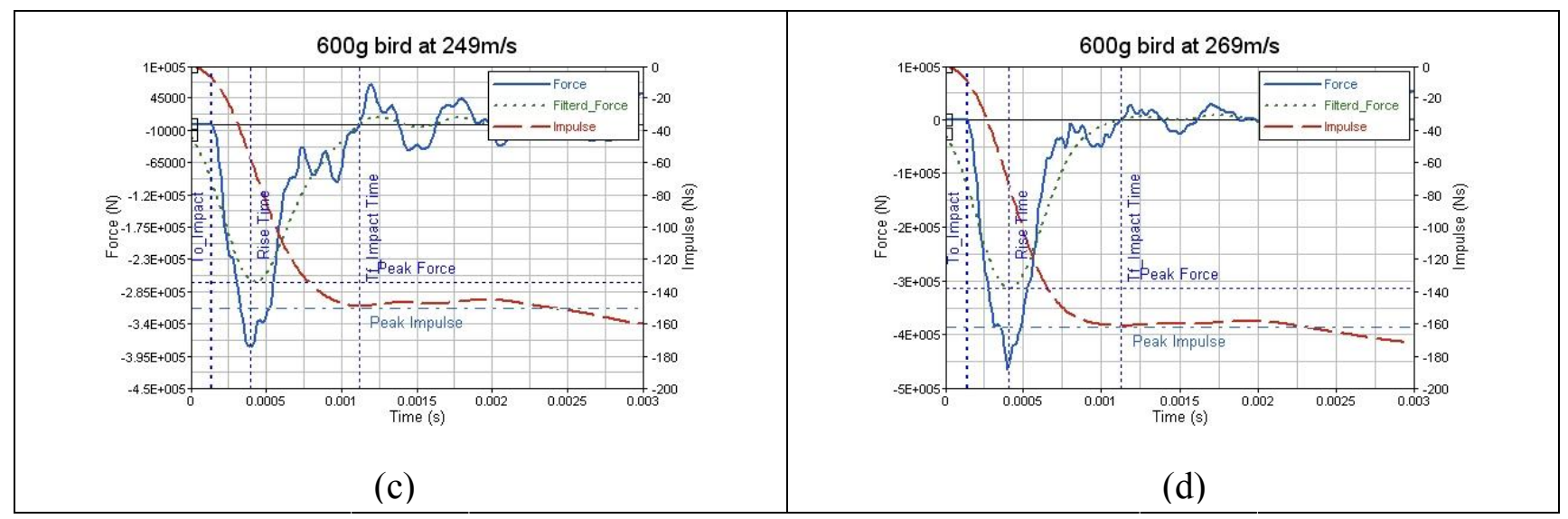

Figure 4.5 Force and Impulse Vs Time at V=192m/s, V=219m/s, V=249m/s, V=269m/s for bird mass $600 \mathrm{~g}$

The peak impulse value obtained from the graph in figure 4.5 and is applied in the following formula to calculate the non-dimensional impulse,

$$
\text { Non-Dimensional Impulse }=\frac{\int F d t}{m v \sin \theta}
$$

Where

$$
\begin{aligned}
& \int F d t=\text { Impulse } \\
& v=\text { Impact velocity } \\
& \theta=\text { Impact angle }
\end{aligned}
$$

The value of impulse is obtained by integrating force vs time curve and peak value is obtained from the figure 4.4 .

For an impact velocity of $192 \mathrm{~m} / \mathrm{s}$, 


$$
\begin{aligned}
\text { Non-Dimensional Impulse } & =\frac{108}{0.6 * 192 * \operatorname{Sin} 90} \\
& =0.937
\end{aligned}
$$

Table 4.5 Values of non-dimensional impulse for bird mass $600 \mathrm{~g}$

\begin{tabular}{|c|c|c|}
\hline Velocity & \multicolumn{2}{|c|}{ Non-Dimensional Impulse } \\
\hline $\mathrm{m} / \mathrm{s}$ & Testing & Simulation \\
\hline 192 & 0.798 & 0.937 \\
\hline 219 & 0.819 & 0.951 \\
\hline 249 & 0.889 & 0.997 \\
\hline 269 & 0.950 & 1.009 \\
\hline
\end{tabular}

The comparison between test data and the simulation for the non-dimensional impulse vs impact velocity is shown in table 4.5 .

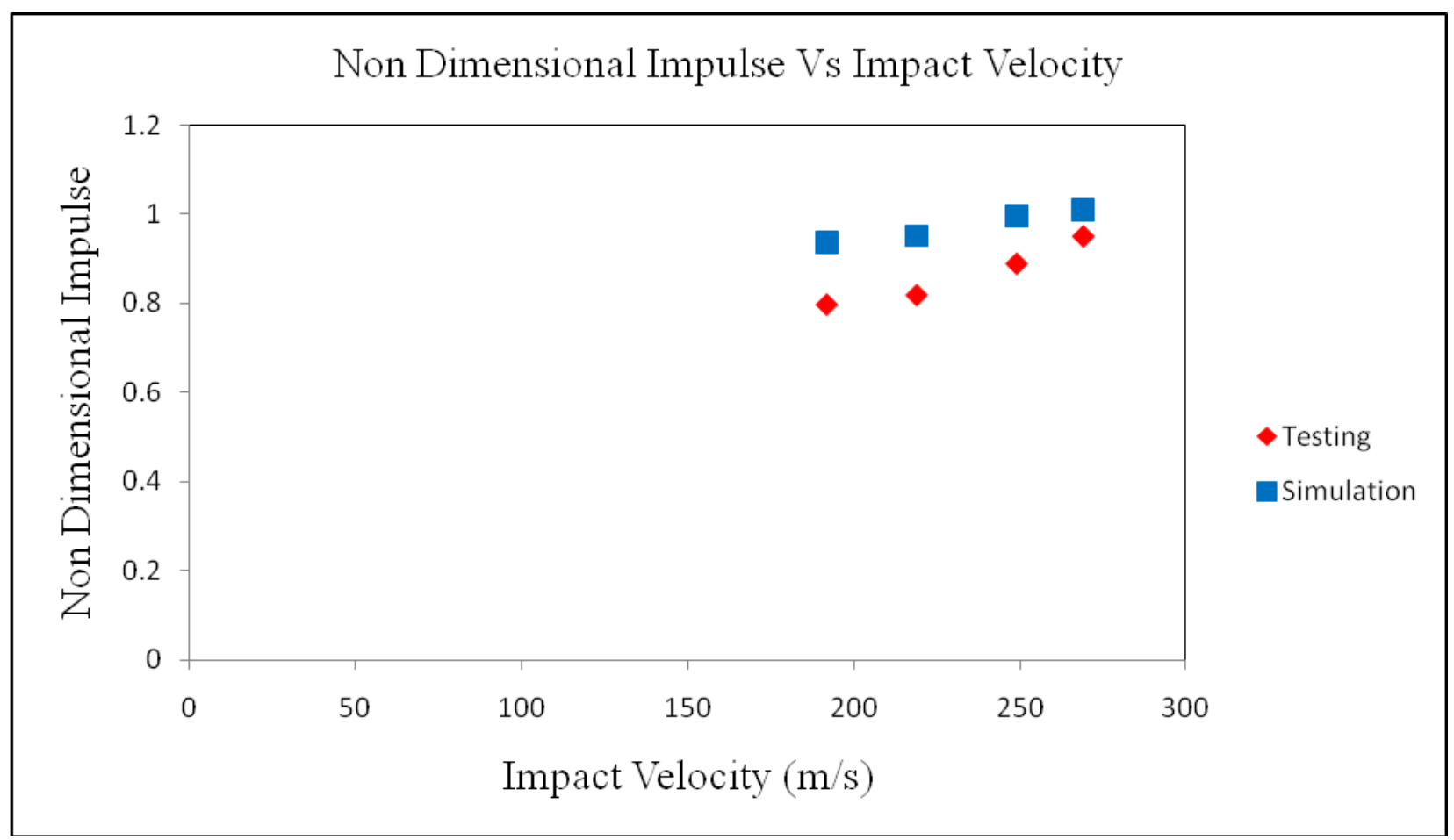

Figure 4.6 Non-dimensional impulse vs impact velocity for bird mass $600 \mathrm{~g}$ 
From the figure it can be observed that testing and simulation value show good co-relation

\subsubsection{Calculation of non-dimensional impact duration:}

Non-dimensional impact duration is calculated by the following formula,

$$
\text { Non-dimensional impact duration }=\frac{T_{s} v}{l_{e f f}}
$$

Where

$$
\begin{aligned}
& l_{\text {eff }}=l+d \tan \theta=\text { Effective length of the bird } \\
& 1=\text { Length of the bird } \\
& \mathrm{d}=\text { Diameter of the bird } \\
& \text { Ts = Squash time }
\end{aligned}
$$

Squash time is calculated from the time when the impact begins when the leading edge of the bird initially comes in contact with the rigid plate and continues till the trailing edge of the bird reaches the target until there is no further bird material flowing at the target. After squash time is determined from the simulation, it is applied in the formula to calculate the nondimensional Impact duration

For impact velocity of $192 \mathrm{~m} / \mathrm{s}$

Non-dimensional impact duration $=\frac{0.00103 * 192}{192}$

$$
=1.03
$$


Non-dimensional impact duration values for different impact velocities is tabulated with test data in table 4.6

Table 4.6 Values of non-dimensional impact duration for bird mass $600 \mathrm{~g}$

\begin{tabular}{|c|c|c|}
\hline Velocity & \multicolumn{2}{|c|}{ Non-Dimensional Impact Duration } \\
\hline $\mathrm{m} / \mathrm{s}$ & Testing & Simulation \\
\hline 192 & 0.786 & 1.03 \\
\hline 219 & 1.041 & 1.105 \\
\hline 249 & 1.115 & 1.270 \\
\hline 269 & 0.864 & 1.457 \\
\hline
\end{tabular}

The comparison between test data and the simulation for the non-dimensional impact duration vs impact velocity is shown in figure 4.7

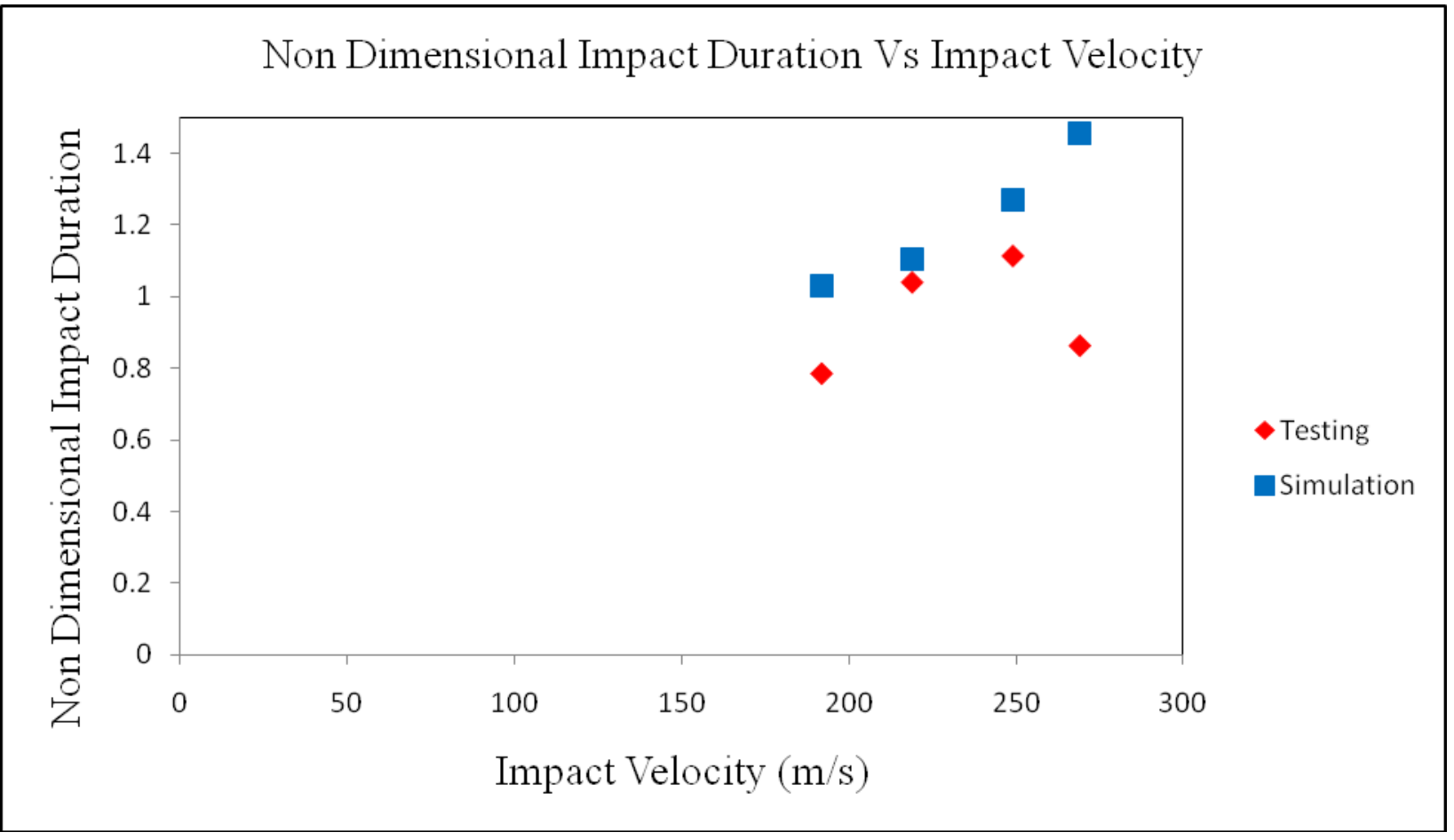


Figure 4.7 Non-dimensional impact duration vs impact velocity for bird mass $600 \mathrm{~g}$

Figure 4.7 shows good co-relation between testing and simulation plots. The non-dimensional impact duration must increase as the impact velocity increases, since the impact velocity is directly proportional to the non-dimensional impact duration. This could be an anomaly in the testing results for impact velocity of $269 \mathrm{~m} / \mathrm{s}$ because there is drop in its magnitude value.

\subsubsection{Calculation of non-dimensional peak force}

The non-dimensional peak force is calculated by using the formula,

Non-dimensional peak force $=\frac{F_{p} l_{\text {eff }}}{m v^{2} \sin \theta}$

Where

$$
\begin{aligned}
& F_{p}=\text { Peak force, obtained from the graph in figure } 4.4 \\
& m=\text { Mass of the bird } \\
& v=\text { Impact velocity } \\
& l_{\text {eff }}=\text { Effective length of the bird }
\end{aligned}
$$

For an impact velocity of $192 \mathrm{~m} / \mathrm{s}$,

$$
\begin{aligned}
\text { Non-dimensional peak force } & =\frac{148995 * 0.192}{0.6 * 192 * 192} \\
& =1.293
\end{aligned}
$$

In table 4.7 the values of non-dimensional rise time for different impact velocities and test data values are tabulated. 
Table 4.7 Values of non-dimensional rise time for bird mass $600 \mathrm{~g}$

\begin{tabular}{|c|c|c|}
\hline Velocity & \multicolumn{2}{|c|}{ Non-Dimensional Rise Time } \\
\hline $\mathrm{m} / \mathrm{s}$ & Testing & Simulation \\
\hline 192 & 1.9102 & 1.293 \\
\hline 219 & 1.8728 & 1.087 \\
\hline 249 & 1.4919 & 1.385 \\
\hline 269 & 1.7839 & 1.391 \\
\hline
\end{tabular}

The non-dimensional peak force is directly proportional to force and inversely proportional to the square of impact velocity. There is some variation in testing and simulation plots and this can be due to large increase in the magnitude of force as the impact velocity is varied.

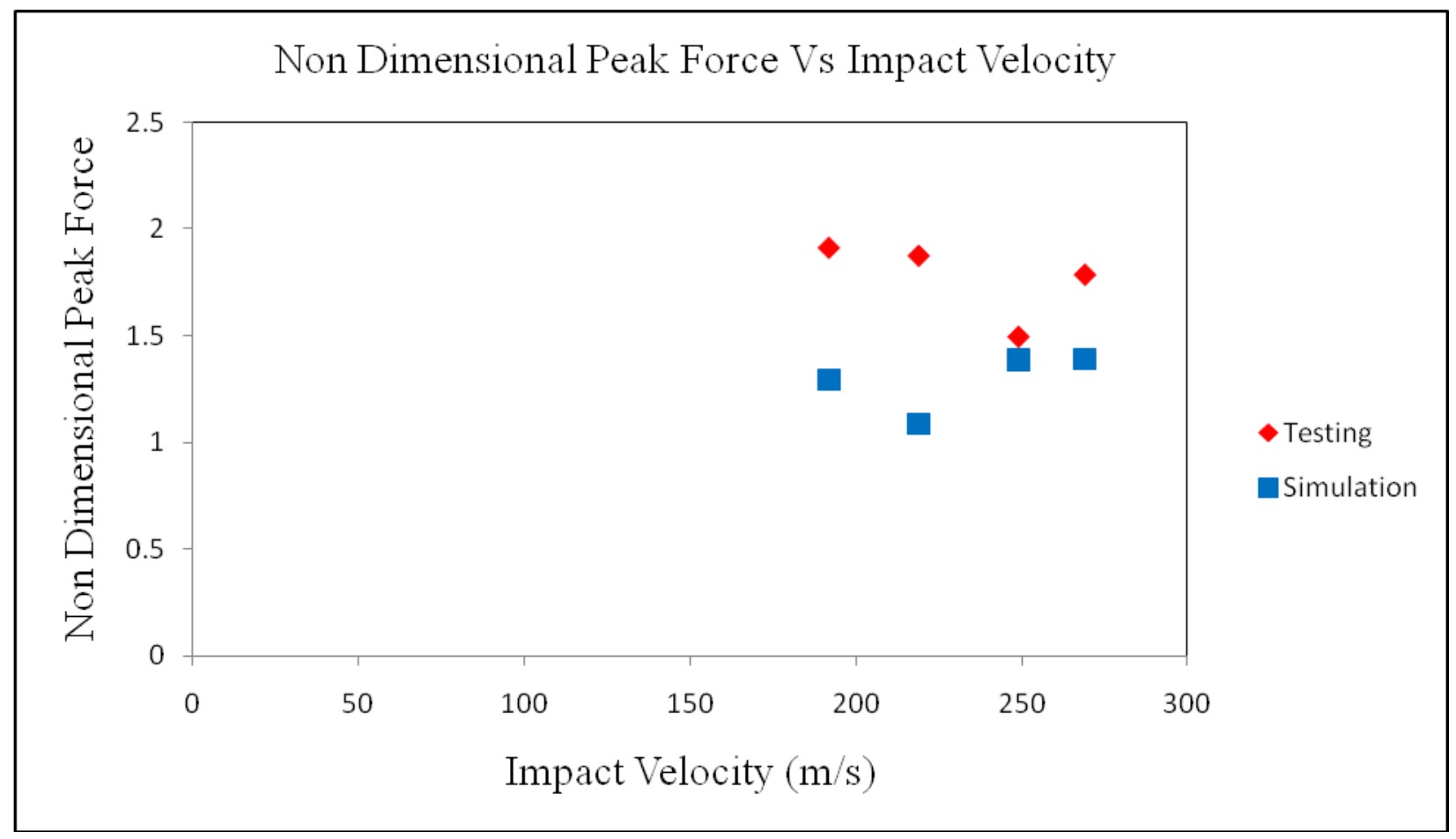

Figure 4.8 Non-dimensional peak force vs impact velocity for bird mass $600 \mathrm{~g}$ 


\subsubsection{Calculation of non-dimensional rise time}

The non-dimensional rise time is calculated from the formula 4.10. Rise time is calculated from the initial point of impact of the bird until the peak force is reached in force vs time graph in figure 4.4 .

$$
\text { Non-dimensional rise time }=\frac{v^{*} T_{R}}{l_{e f f}}
$$

For an impact velocity of $192 \mathrm{~m} / \mathrm{s}$,

Non-dimensional rise time $=\frac{192 * 0.00027}{0.192}$

$$
=0.27
$$

Table 4.8 Values of non-dimensional rise time for bird mass $600 \mathrm{~g}$

\begin{tabular}{|c|c|c|}
\hline Velocity & \multicolumn{2}{|c|}{ Non-Dimensional Rise Time } \\
\hline $\mathrm{m} / \mathrm{s}$ & Testing & Simulation \\
\hline 192 & 0.206 & 0.270 \\
\hline 219 & 0.199 & 0.285 \\
\hline 249 & 0.238 & 0.337 \\
\hline 269 & 0.457 & 0.371 \\
\hline
\end{tabular}

The non-dimensional rise time values for other impact velocities are tabulated with test data in table 4.8. 
The graph of non-dimensional rise time vs impact velocity is plotted in figure 4.9 and plot shows good co-relation between testing and simulation result.

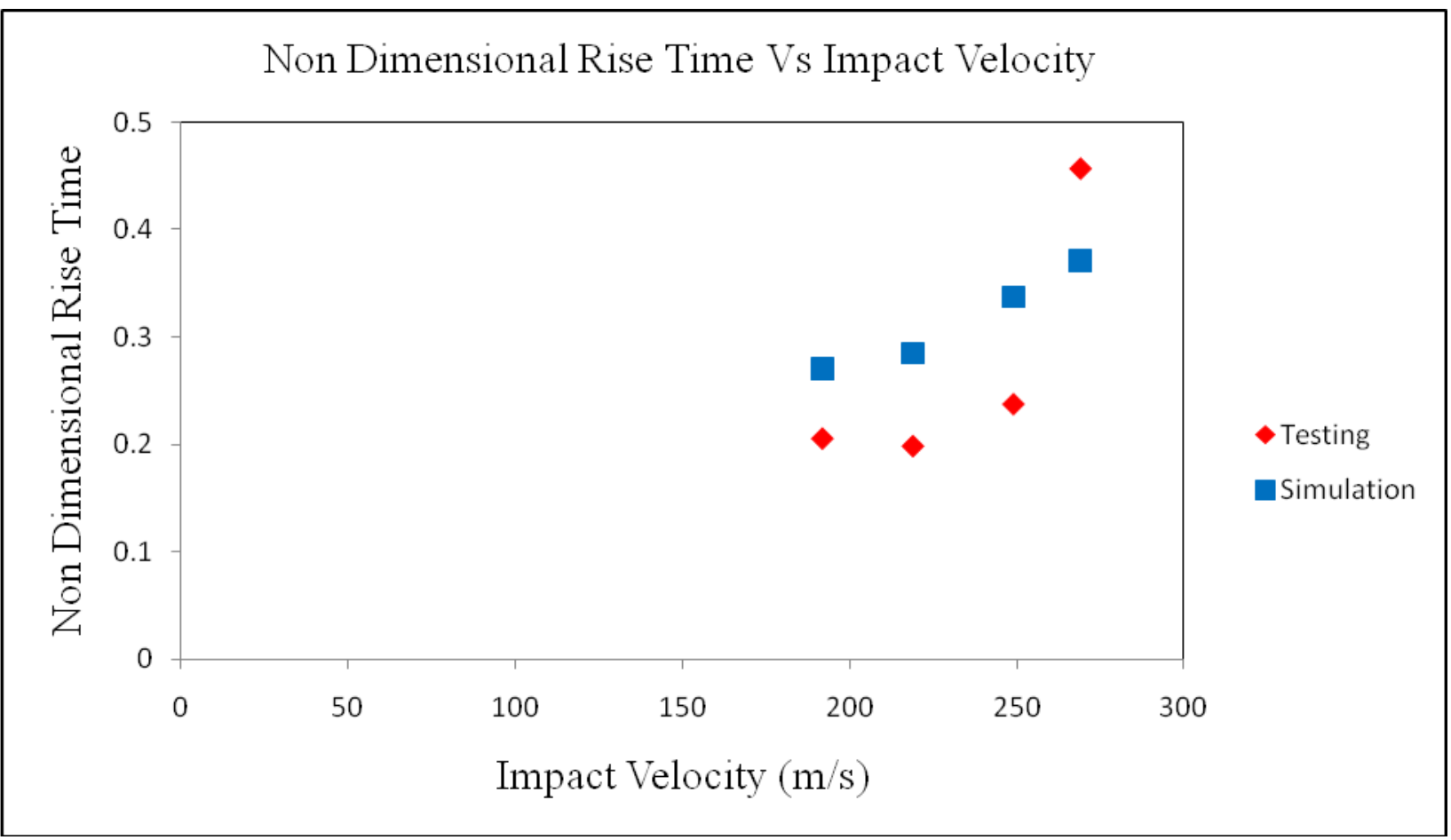

Figure 4.9 Non-dimensional rise time vs impact velocity for bird mass $600 \mathrm{~g}$

\subsection{Birdstrike setup with bird mass of $1.81 \mathrm{Kg}$ with pitch distance $4 \mathrm{~mm}$ and $10 \mathrm{~mm}$.}

The bird of mass $1.81 \mathrm{~kg}(4-1 \mathrm{~b})$ is impacted on the target plate which is held normal. Two different bird models are used with pitch distance of $4 \mathrm{~mm}$ and pitch distance of $10 \mathrm{~mm}$ and the effect of pitch can be analyzed by comparing the results.

In figure 4.10 the two bird models of mass $4-1 \mathrm{~b}$ and pitch distance $4 \mathrm{~mm}$ and $10 \mathrm{~mm}$ are shown. The difference between the two models is the distance between two SPH particles. Thus for pitch distance $10 \mathrm{~mm}$ there are less number of SPH particles when compared with pitch distance $4 \mathrm{~mm}$. Figure 4.10 (a) which has pitch distance of $4 \mathrm{~mm}$ has 30038 particles and figure 4.10 (b) of pitch 
distance $10 \mathrm{~mm}$ has 1791 particles. Both the bird models have length of $287 \mathrm{~mm}$ and diameter of $98 \mathrm{~mm}$.

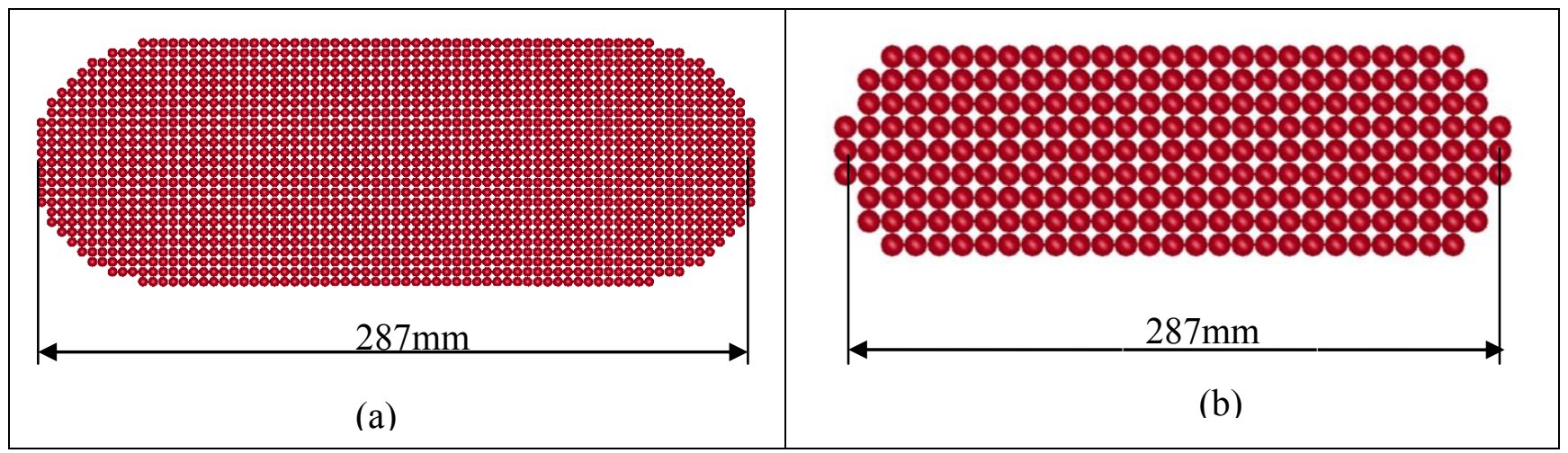

Figure 4.10 Bird impact on rigid plate of pitch $4 \mathrm{~mm}$ for bird mass $1.81 \mathrm{Kg}$

The $4 \mathrm{lb}$ bird $0 \mathrm{f}$ pitch $4 \mathrm{~mm}$ and $10 \mathrm{~mm}$ is impacted on the plate target with $200 \mathrm{~m} / \mathrm{s}, 250 \mathrm{~m} / \mathrm{s}$ and $300 \mathrm{~m} / \mathrm{s}$ and results are analyzed for both the bird models.

\subsubsection{Calculation of non-dimensional impulse:}

The non-dimensional impulse is calculated for the 4-lb bird with pitch $4 \mathrm{~mm}$ and $10 \mathrm{~mm}$ and plotted against impact velocity. It is calculated using the formula

$$
\text { Non-dimensional impulse }=\frac{\int F d t}{m v \sin \theta}
$$

For an impact velocity of $200 \mathrm{~m} / \mathrm{s}$,

$$
\begin{aligned}
\text { Non-dimensional impulse } & =\frac{348}{1.81 * 200 * \sin 90} \\
& =0.960
\end{aligned}
$$


Similarly non-dimensional impulse values for other velocities are calculated and tabulated in table 4.9.

Table 4.9 Values of non-dimensional impulse for bird mass $1.81 \mathrm{Kg}$

\begin{tabular}{|c|c|c|}
\hline Velocity & \multicolumn{2}{|c|}{ Non-Dimensional Impulse } \\
\hline $\mathrm{m} / \mathrm{s}$ & \multicolumn{2}{|c|}{ Simulation } \\
\hline & Pitch 4mm & Pitch $10 \mathrm{~mm}$ \\
\hline 200 & 0.960 & 0.943 \\
\hline 250 & 0.993 & 0.964 \\
\hline 300 & 1.011 & 0.997 \\
\hline
\end{tabular}

The plot of non-dimensional impulse vs impact velocity for pitch of $4 \mathrm{~mm}$ and $10 \mathrm{~mm}$ are plotted.

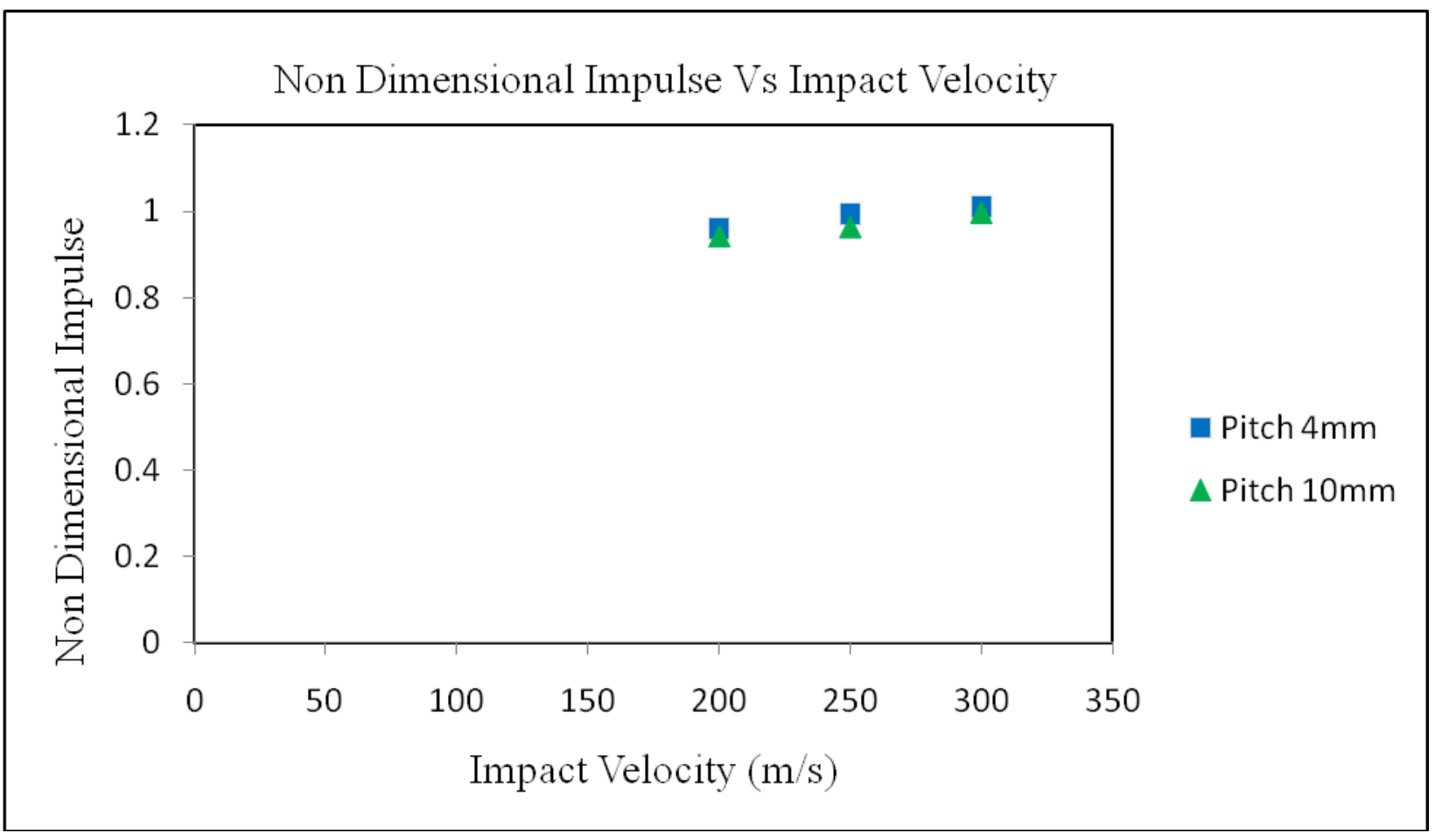

Figure 4.11 Non-dimensional impulse vs impact velocity for bird mass $1.81 \mathrm{Kg}$. 
From the graph it can be analyzed that non-dimensional impulse values almost overlap for pitch of $4 \mathrm{~mm}$ and $10 \mathrm{~mm}$ and there is no variation is observed.

\subsubsection{Calculation of non-dimensional impact duration:}

$$
\begin{aligned}
& \text { Non-dimensional impact duration }=\frac{T_{s} v}{l_{e f f}} \\
& l_{\text {eff }}=l+d \tan \theta=\text { Effective length of the bird } \\
& l=\text { Length of the bird } \\
& d=\text { Diameter of the bird } \\
& T_{s}=\text { Squash time } \\
& v=\text { Impact velocity }
\end{aligned}
$$

Squash time is calculated from the time when the impact begins when the leading edge of the bird initially comes in contact with the rigid plate and continues till the trailing edge of the bird reaches the target until there is no further bird material flowing at the target

For an impact velocity of $200 \mathrm{~m} / \mathrm{s}$,

Non-dimensional impact duration $=\frac{0.00134 * 200}{0.287}$

$$
=0.933
$$

Similarly, non-dimensional impact duration values for other velocities are determined and tabulated in table 4.10 . 
Table 4.10 Values of non-dimensional impact duration for bird mass $1.81 \mathrm{Kg}$

\begin{tabular}{|c|c|c|}
\hline Velocity & \multicolumn{2}{|c|}{ Non-Dimensional Impact Duration } \\
\hline $\mathrm{m} / \mathrm{s}$ & \multicolumn{2}{|c|}{ Simulation } \\
\hline & Pitch $4 \mathrm{~mm}$ & Pitch $10 \mathrm{~mm}$ \\
\hline 200 & 0.933 & 0.947 \\
\hline 250 & 0.940 & 0.949 \\
\hline 300 & 1.045 & 1.087 \\
\hline
\end{tabular}

The impact velocity is directly proportional to non-dimensional impact duration and thus we can observe from the plots that as velocity increases the non-dimensional impact duration increases and there is not much variation in plots between pitch $4 \mathrm{~mm}$ and pitch $10 \mathrm{~mm}$.

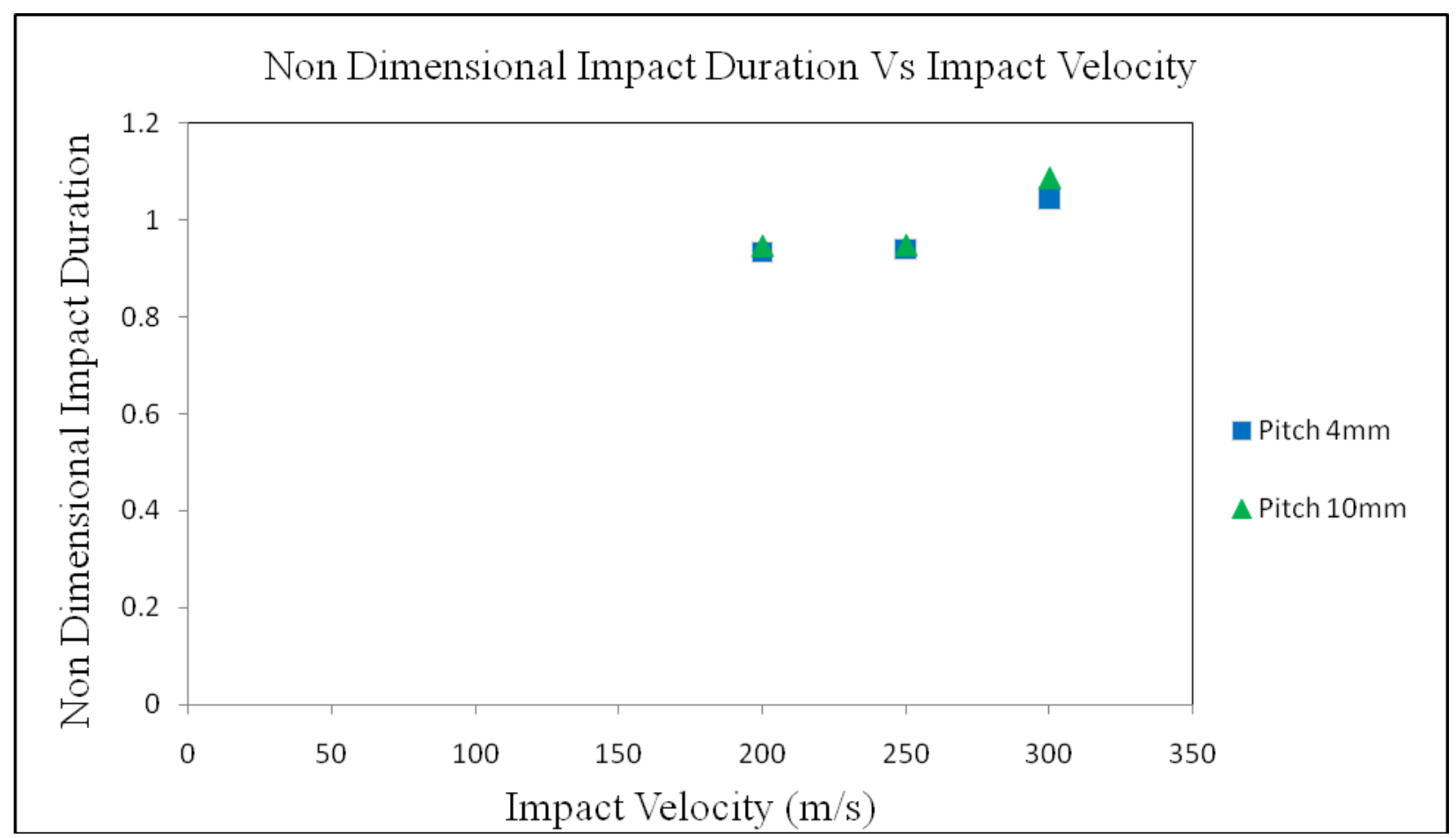

Figure 4.12 Non-dimensional impact duration vs impact velocity for bird mass $1.81 \mathrm{Kg}$ 


\subsubsection{Calculation of non-dimensional peak force:}

The non-dimensional peak force is obtained by determing the peak force from force vs time plot and substituting in the formula,

$$
\text { Non-dimensional peak force }=\frac{F_{p} l_{e f f}}{m v^{2} \sin \theta}
$$

Where

$$
\begin{aligned}
& F_{p}=\text { Peak force } \\
& m=\text { Mass of the bird } \\
& v=\text { Impact velocity } \\
& \theta=\text { Impact angle } \\
& l_{\text {eff }}=\text { Effective length of the bird }
\end{aligned}
$$

For an impact velocity of $200 \mathrm{~m} / \mathrm{s}$

$$
\begin{aligned}
\text { Non-dimensional peak force } & =\frac{341360 * 0.287}{1.81 * 200 * 200 * \operatorname{Sin} 90} \\
& =1.351
\end{aligned}
$$

Similarly, non-dimensional peak force values are determined for other impact velocities and results are tabulated in table 4.11 . 
Table 4.11 Values of non-dimensional impact duration for bird mass $1.81 \mathrm{Kg}$

\begin{tabular}{|c|c|c|}
\hline Velocity & \multicolumn{2}{|c|}{ Non-Dimensional Impact Duration } \\
\hline $\mathrm{m} / \mathrm{s}$ & \multicolumn{2}{|c|}{ Simulation } \\
\hline & Pitch $4 \mathrm{~mm}$ & Pitch $10 \mathrm{~mm}$ \\
\hline 200 & 1.351 & 1.305 \\
\hline 250 & 1.358 & 1.298 \\
\hline 300 & 1.368 & 1.310 \\
\hline
\end{tabular}

The non-dimensional peak force is directly proportional to the force and inversely proportional to the square of impact velocity and no variation is observed between two models of pitch $4 \mathrm{~mm}$ and $10 \mathrm{~mm}$.

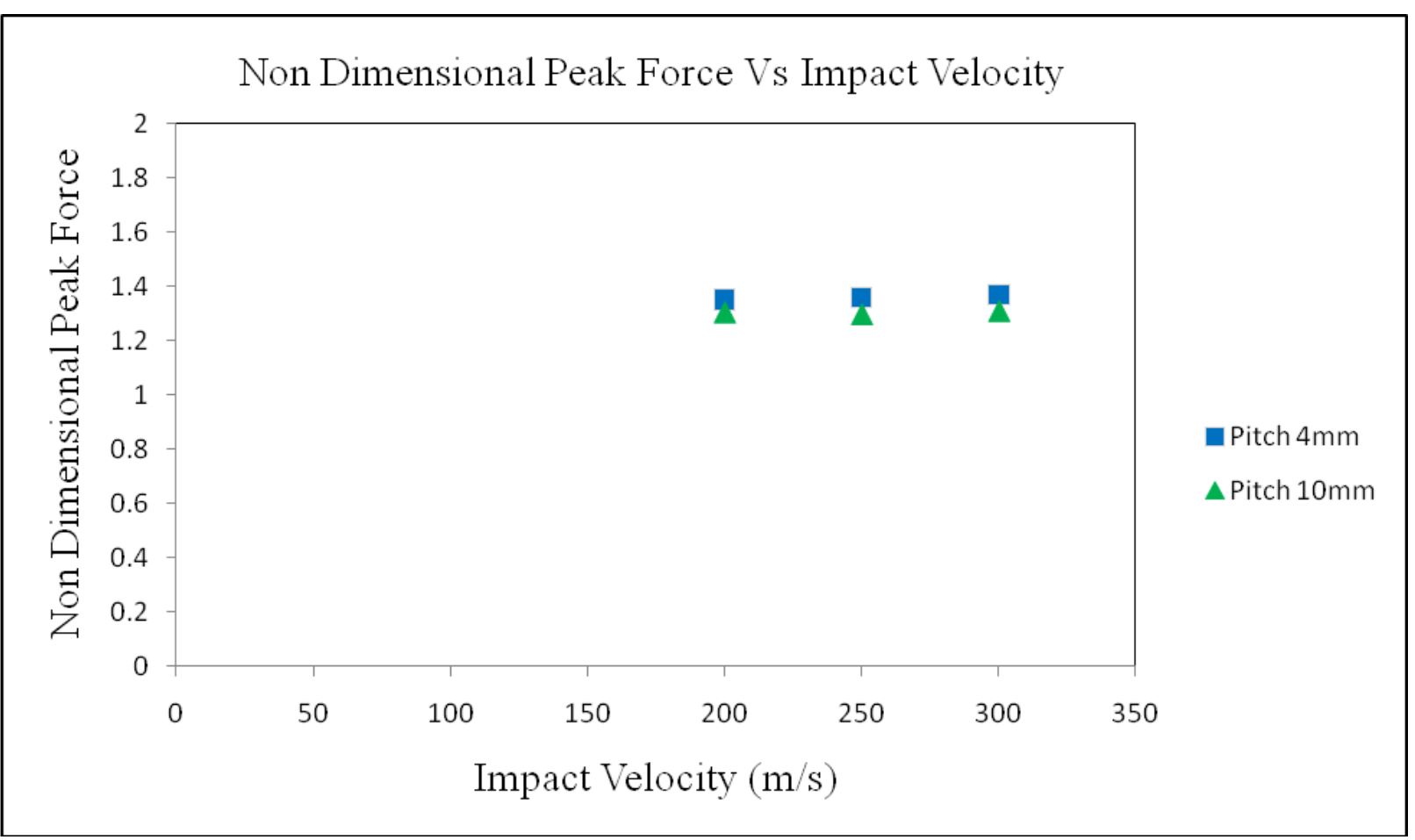

Figure 4.13 Non-dimensional peak force vs impact velocity for bird mass $1.81 \mathrm{Kg}$ 


\subsubsection{Calculation of non-dimensional rise time:}

The non-dimensional rise time is calculated by using the formula,

$$
\text { Non-dimensional rise time }=\frac{v^{*} T_{R}}{l_{e f f}}
$$

The rise time is calculated from the instant of impact of the bird till the peak force is reached in force vs time plot.

For an impact velocity of $200 \mathrm{~m} / \mathrm{s}$,

$$
\begin{aligned}
\text { Non-dimensional rise time }= & \frac{200 * 0.0027}{0.287} \\
& =0.188
\end{aligned}
$$

Similarly, non-dimensional rise time values for other impact velocities are calculated and tabulated in table 4.12 .

Table 4.12 Values of non-dimensional rise time for bird mass $1.81 \mathrm{Kg}$

\begin{tabular}{|c|c|c|}
\hline Velocity & \multicolumn{2}{|c|}{ Non-Dimensional Rise Time } \\
\hline $\mathrm{m} / \mathrm{s}$ & \multicolumn{2}{|c|}{ Simulation } \\
\hline & Pitch $4 \mathrm{~mm}$ & Pitch $10 \mathrm{~mm}$ \\
\hline 200 & 0.188 & 0.195 \\
\hline 250 & 0.217 & 0.235 \\
\hline 300 & 0.261 & 0.261 \\
\hline
\end{tabular}


The non-dimensional rise time is directly proportional to rise time and impact velocity and hence non-dimensional rise time increases as the impact velocity increases. There is no difference observed between the two bird models of pitch $4 \mathrm{~mm}$ and $10 \mathrm{~mm}$.

Hence for birdstrike analysis the pitch distance does not affect the simulation results

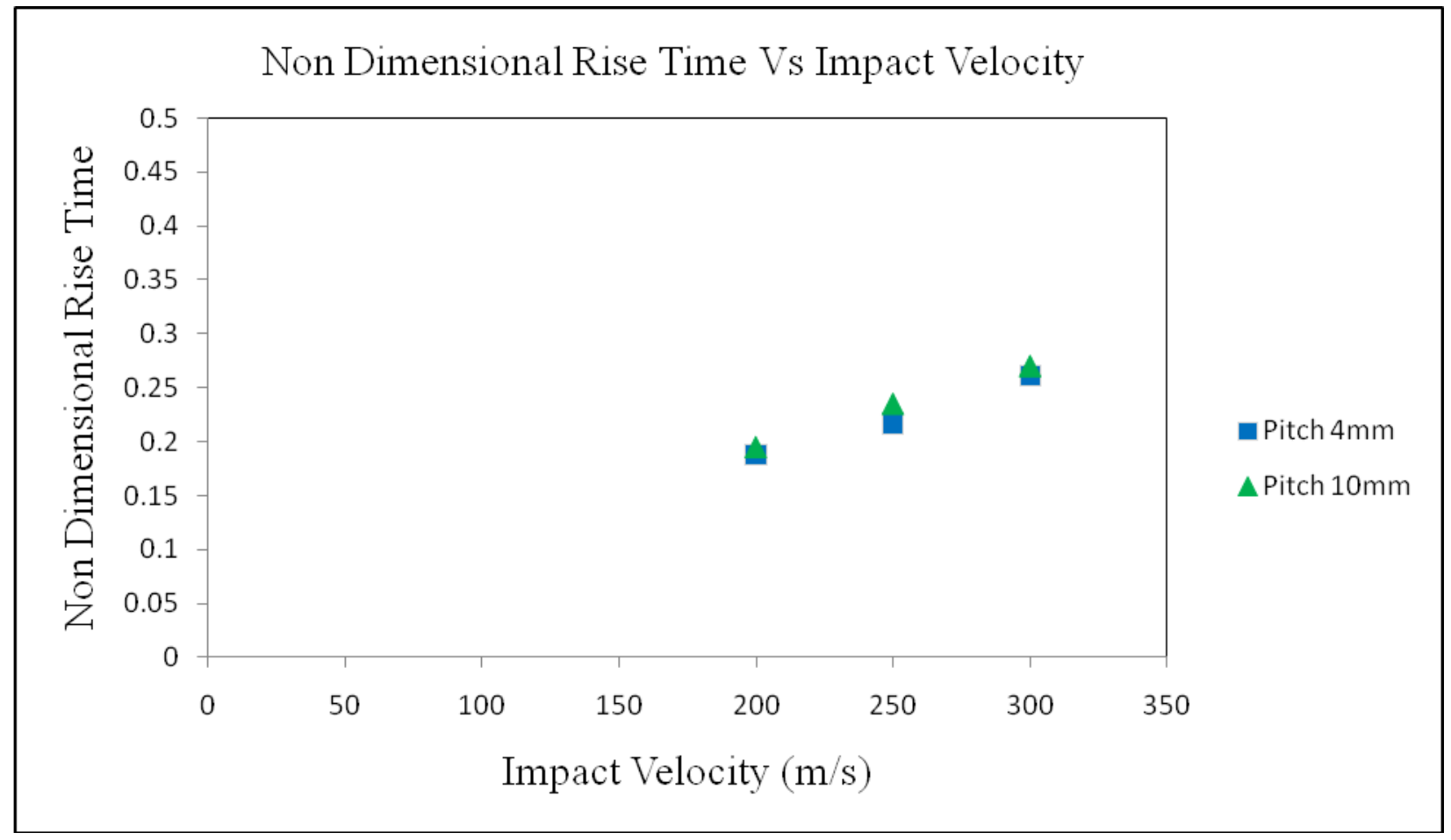

Figure 4.14 Non-dimensional rise time vs impact velocity for bird mass $1.81 \mathrm{Kg}$ 


\section{CHAPTER 5}

\section{BIRDSTRIKE ON LEADING EDGE OF AIRCRAFT WING}

The validated SPH bird model is impacted on the leading edge of varying nose radius of $12.7 \mathrm{~mm}, 62 \mathrm{~mm}$ and $64 \mathrm{~mm}$. The modeling of the leading edge is carried out in CATIA V5 and meshing and connections are defined in Hypermesh. The connections between different parts of leading edge are given using spotwelds and beam elements. The bird is impacted at the leading edge at an angle of 30 degree. The dimensions of all the components are obtained from the literature [20].

The comparison between testing and simulation is carried out for following 3 cases at different impact velocities. The thickness for different parts of leading edge of varying nose radius is listed in table 5.1

Table 5.1 Thickness of leading edge parts for different nose radius [20]

\begin{tabular}{|c|c|c|c||c|c|c|}
\hline Nose Radius & LE Skin & Main Skin & LE Rib & Main Rib & Rib Pitch & Impact Velocity \\
\hline $\mathrm{mm}$ & $\mathrm{mm}$ & $\mathrm{mm}$ & $\mathrm{mm}$ & $\mathrm{mm}$ & $\mathrm{mm}$ & knots \\
\hline 12.7 & 2.03 & 2.03 & 1.22 & 1.22 & 203.2 & 261 \\
\hline 62 & 2.03 & 2.03 & 1.22 & 1.22 & 203.2 & 427 \\
\hline 64 & 3.25 & 3.25 & 1.62 & 1.62 & 203.2 & 341 \\
\hline & & & & & & 294 \\
\hline
\end{tabular}


The exploded view of leading edge with different parts is shown in figure 4.1.

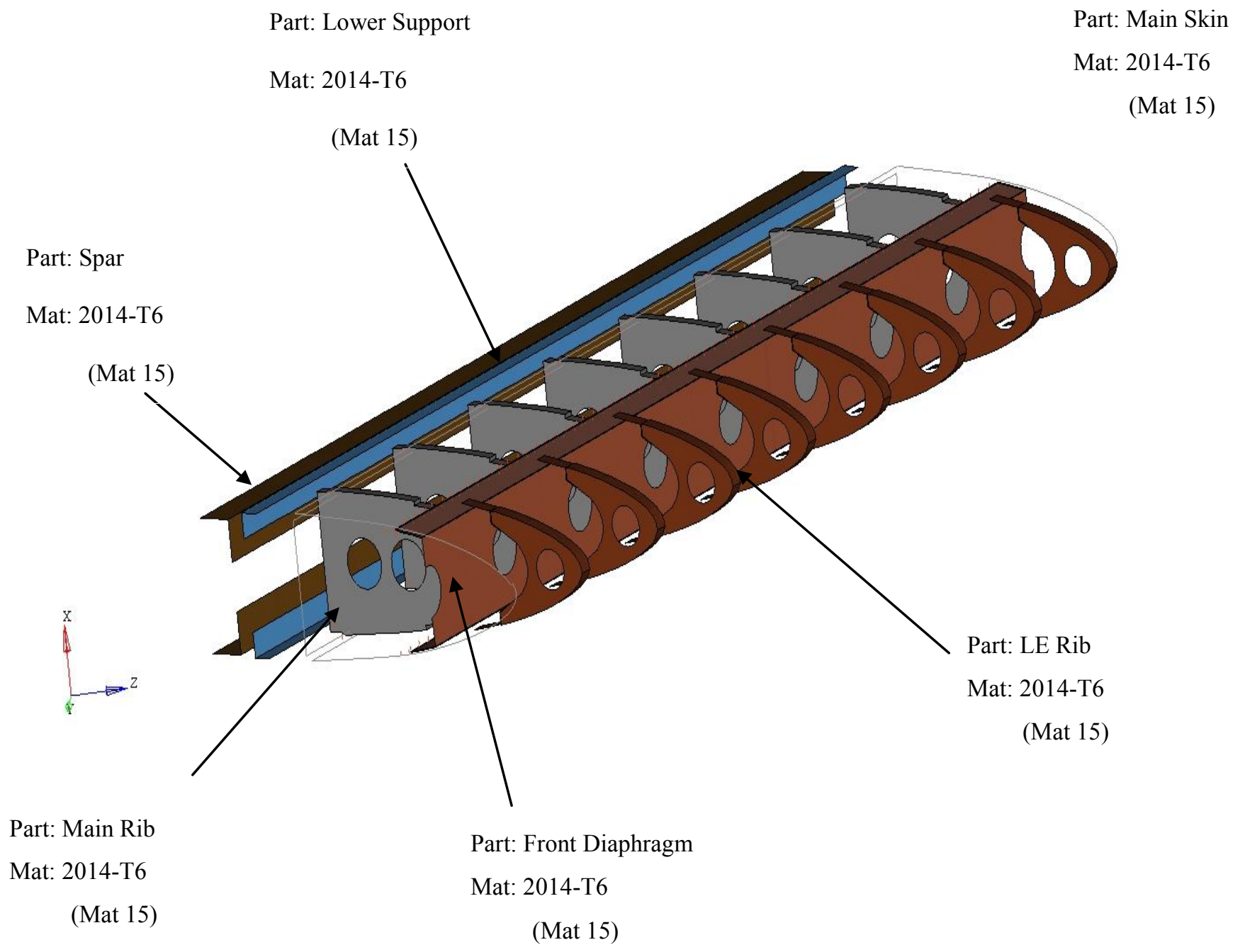

Figure 5.1 Exploded view of leading edge. 


\subsection{Birdstrike on leading edge of nose radius $12.7 \mathrm{~mm}$}

A 4-lb bird of pitch $4 \mathrm{~mm}$ is impacted with velocity of 261 knots and 427 knots on the leading edge of nose radius $12.7 \mathrm{~mm}$ and results are analyzed by comparing it with the results from test data.

In figure 5.2 (a) the front view of the birdstrike set-up is shown and figure 5.2 (b) and 5.2 (c) shows the top view and profile views of the set-up.

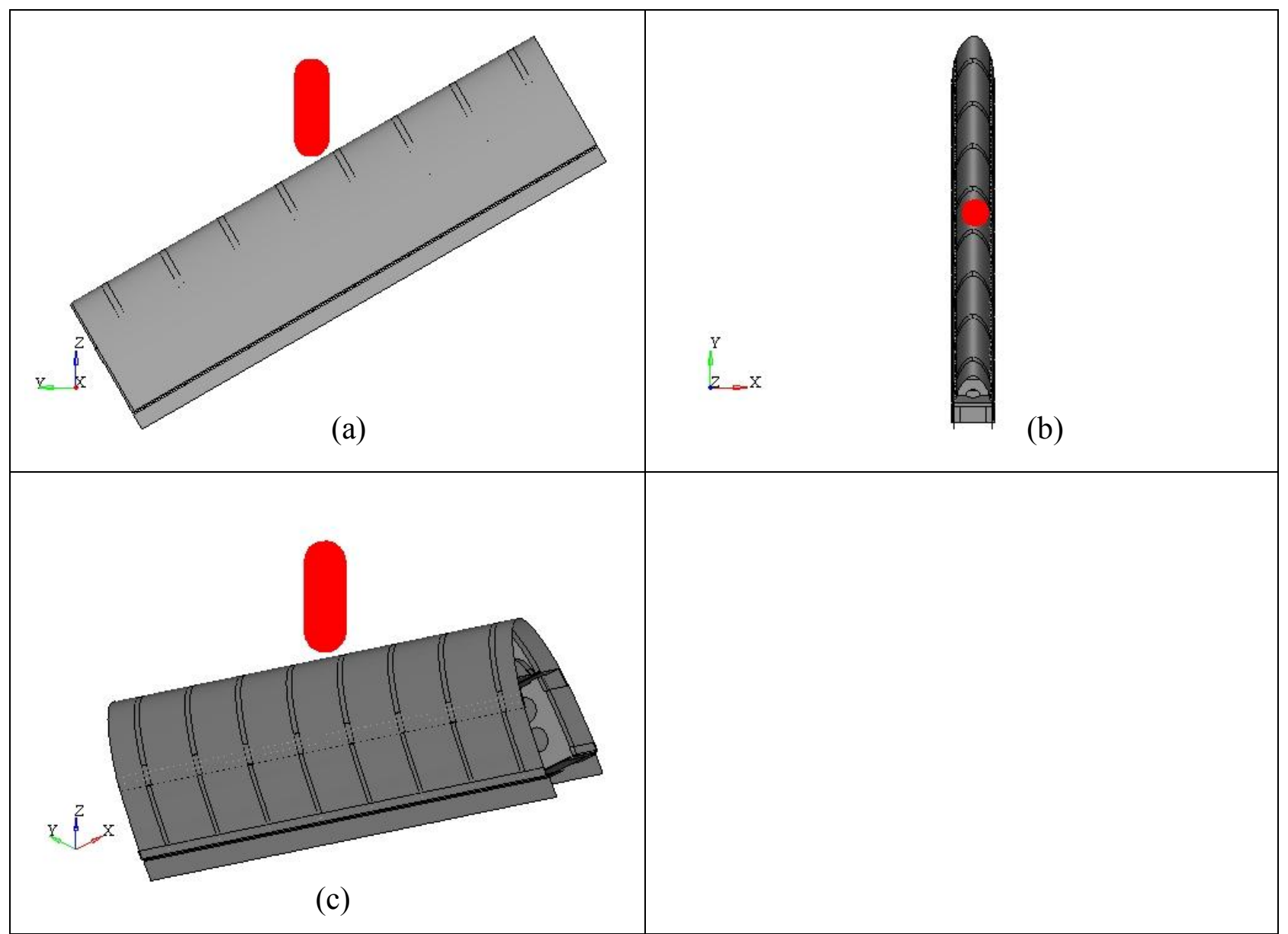

Figure 5.2 Different views of setup of nose radius $12.7 \mathrm{~mm}$. 


\subsubsection{Birdstrike with impact velocity of 261 knots}

In this case the bird strike is carried out by impacting the 4-lb bird with leading edge of nose radius $12.7 \mathrm{~mm}$ at an impact velocity 261 knots. The analysis is carried out for $5 \mathrm{~ms}$ and in figure 5.3 the birdstrike process at the instant of each milli-second is shown.

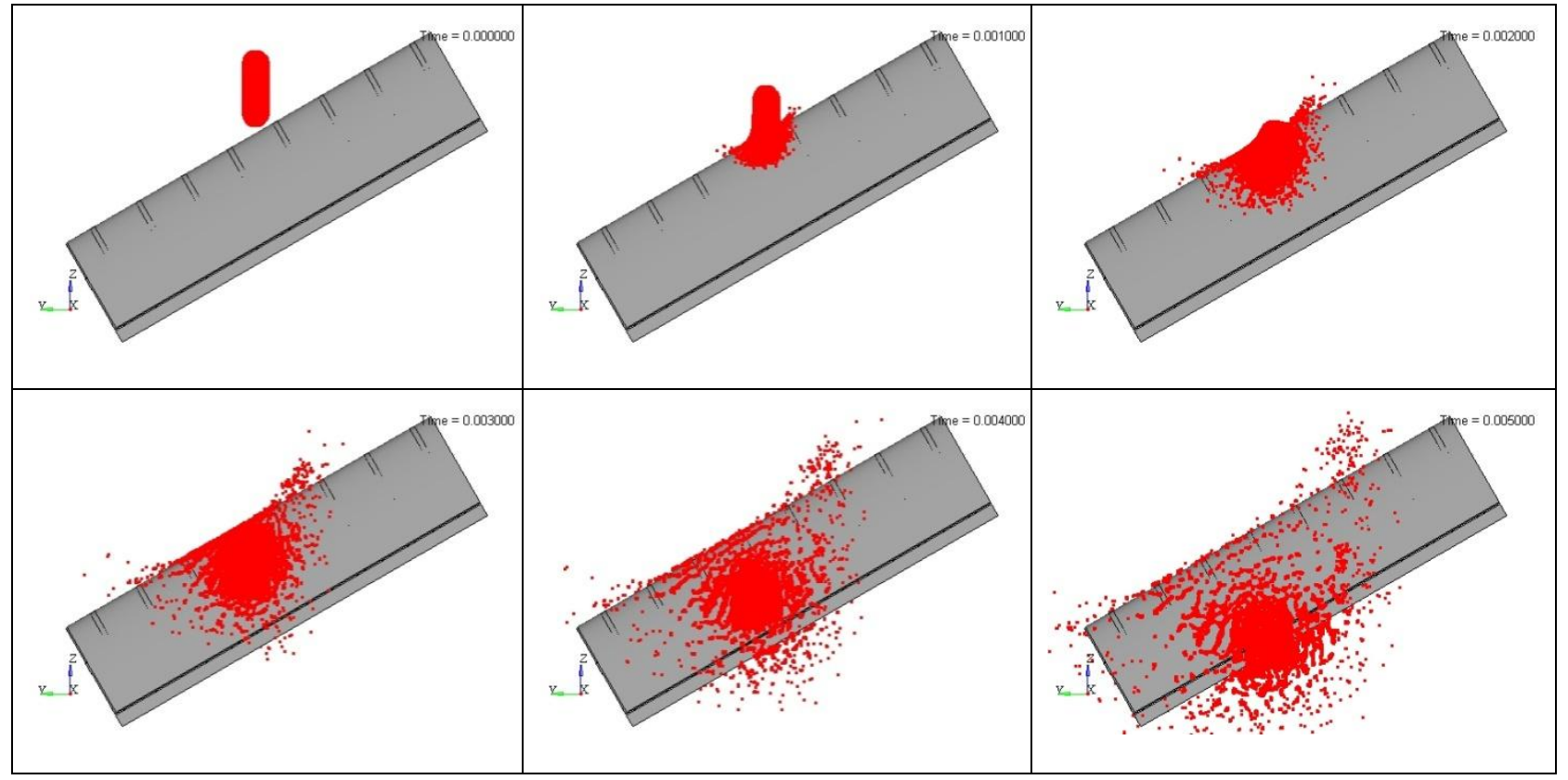

Figure 5.3 Frames at different instants of time for impact velocity 261 knots

In table 5.2 it can be observed that there is no damage on leading edge skin both in test and simulation. It can be observed that damage on diaphragm, spar and leading edge match the test data and simulation results with no damage on any of them. Thus there is good co relation of results between the test and simulation for leading edge of nose radius $12.7 \mathrm{~mm}$ at an impact velocity 261 knots. 
Table 5.2 Comparison of testing and simulation at impact velocity 261 knots

\begin{tabular}{|c|c||c|c|c|c|}
\hline Material & $\begin{array}{c}\text { Velocity } \\
\text { (knots) }\end{array}$ & $\begin{array}{c}\text { Damage on } \\
\text { Leading edge skin }\end{array}$ & $\begin{array}{c}\text { Damage on } \\
\text { Diaphragm }\end{array}$ & $\begin{array}{c}\text { Damage on } \\
\text { Spar }\end{array}$ & $\begin{array}{c}\text { Damage on } \\
\text { Leading edge ribs }\end{array}$ \\
\hline $\begin{array}{c}\text { Testing } \\
\text { 2014-T6 }\end{array}$ & 261 & None & None & None & None \\
\hline $\begin{array}{c}\text { Simulation } \\
\text { 2014-T6 }\end{array}$ & 261 & None & None & None & None \\
\hline
\end{tabular}

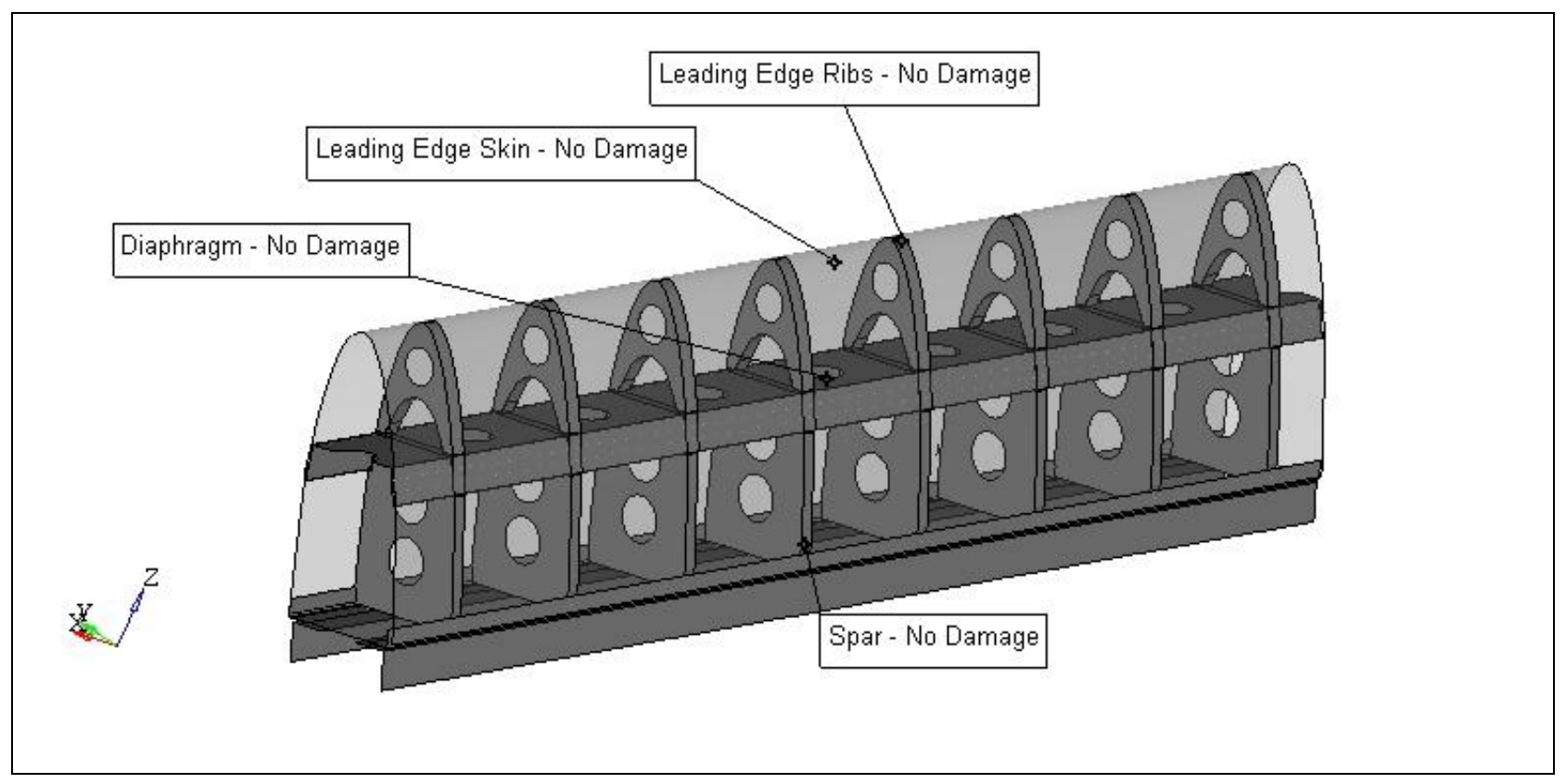

Figure 5.4 Leading edge of $12.7 \mathrm{~mm}$ nose radius.

In figure 5.4 the condition of the leading edge specimen of $12.7 \mathrm{~mm}$ nose radius is shown and its parts are highlighted. 


\subsubsection{Birdstrike with impact velocity of 427 knots.}

The birdstrike is carried out on leading edge of nose radius $12.7 \mathrm{~mm}$ with impact velocity of 427 knots with bird mass of 4-lb. In figure 5.5 the kinematics of the bird at instants of each milli-second are shown.

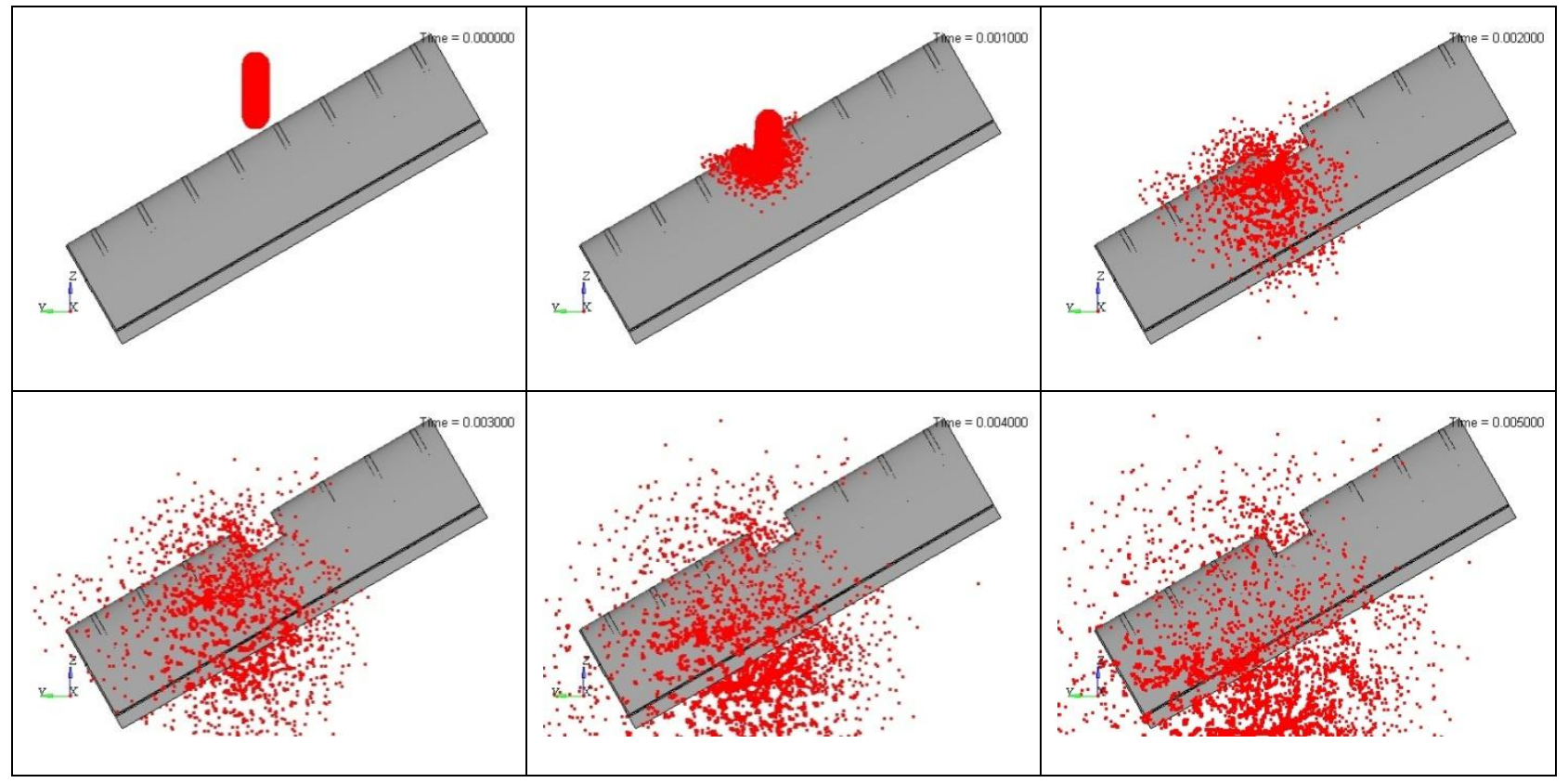

Figure 5.5 Frames at different instants of time for impact velocity 427 knots.

In table 5.3 the comparison of results between test data and simulation results is shown.

We can observe that leading edge is torn along rivet line for both in test data and simulation. In the test two bays are torn along the diaphragm and in simulation one bay is torn and one is partially torn. There is no damage observed on spar for both in test and simulation results. And in case of leading edge ribs, one is torn off and one is buckled for both simulation and test results. Thus it can be observed that there is reasonable co-relation between testing and simulation results. 
Table 5.3 Comparison of testing and simulation at impact velocity 427 knots.

\begin{tabular}{|c|c|c|c|c|c|}
\hline Material & $\begin{array}{l}\text { Velocity } \\
\text { (knots) }\end{array}$ & $\begin{array}{l}\text { Damage on } \\
\text { Leading edge } \\
\text { skin }\end{array}$ & $\begin{array}{l}\text { Damage on } \\
\text { Diaphragm }\end{array}$ & $\begin{array}{l}\text { Damage on } \\
\text { Spar }\end{array}$ & $\begin{array}{c}\text { Damage on Leading } \\
\text { edge ribs }\end{array}$ \\
\hline $\begin{array}{c}\text { Test } \\
\text { 2014-T6 }\end{array}$ & 427 & $\begin{array}{l}\text { Torn along rivet } \\
\text { line }\end{array}$ & 2 bays torn & None & $\begin{array}{l}1 \text { torn off } \\
1 \text { buckled }\end{array}$ \\
\hline $\begin{array}{l}\text { Simulation } \\
2014-T 6\end{array}$ & 427 & $\begin{array}{l}\text { Torn along rivet } \\
\text { line }\end{array}$ & $\begin{array}{l}1 \text { bay torn } \\
\text { and } 1 \\
\text { partially torn }\end{array}$ & None & $\begin{array}{l}1 \text { torn off } \\
1 \text { buckled }\end{array}$ \\
\hline
\end{tabular}

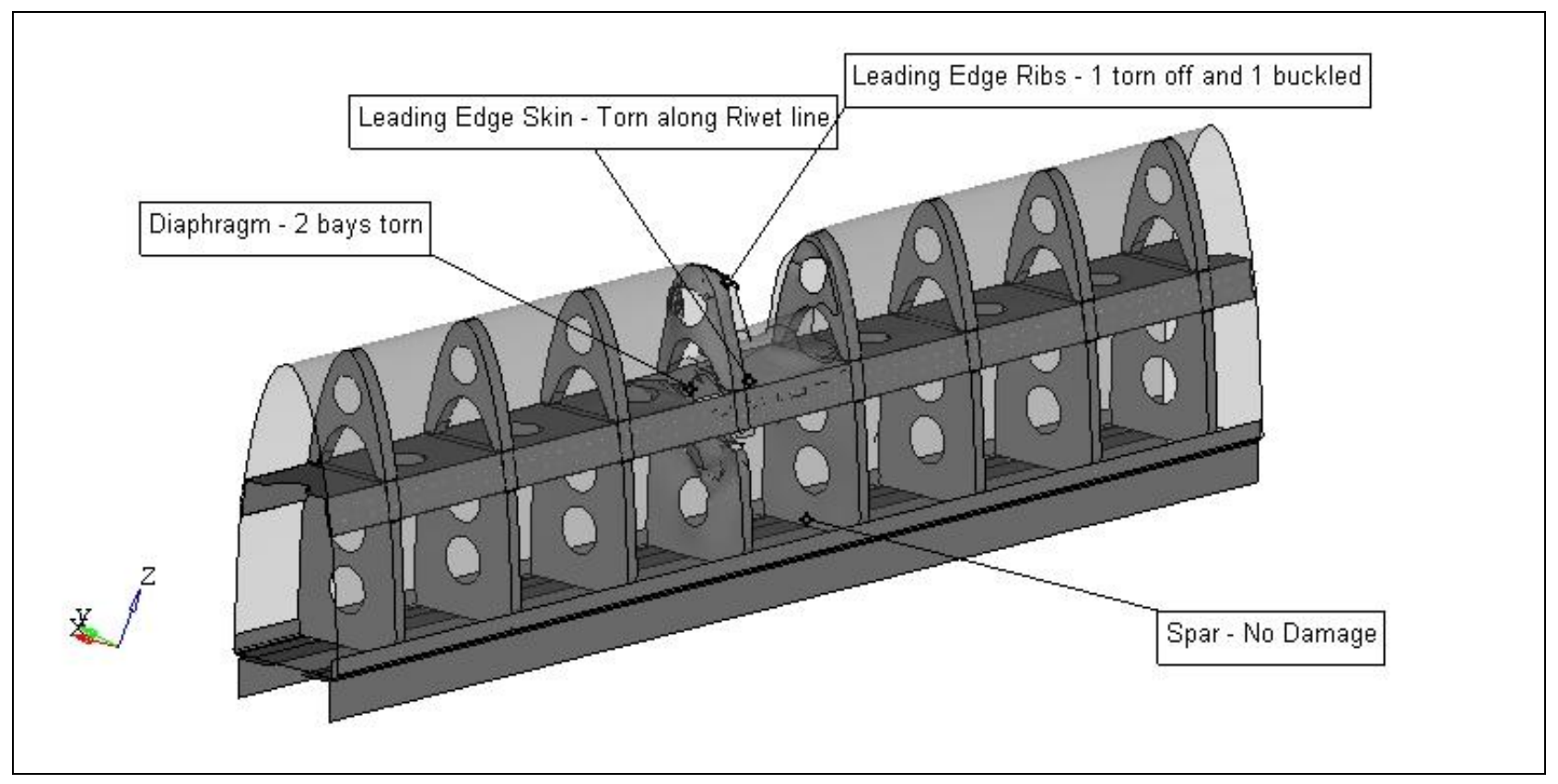

Figure 5.6 Leading edge of $12.7 \mathrm{~mm}$ nose radius

In figure 5.6, structure of the leading edge at the end of analysis is shown where the damage on leading edge skin, leading edge ribs, spar and diaphragm are observed. 


\subsection{Birdstrike on leading edge of nose radius $62 \mathrm{~mm}$.}

A 4-1b bird of pitch $4 \mathrm{~mm}$ is impacted on leading edge of nose radius $62 \mathrm{~mm}$ with velocity of 146 knots and 294 knots and results are analyzed by comparing it with the results from test data.

The birdstrike set up is shown in different views in figure 5.7. In figure 5.7 (a) the front view of the setup is shown and in figure 5.7 (b) and 5.7 (c) shows the front and profile views of the set-up.

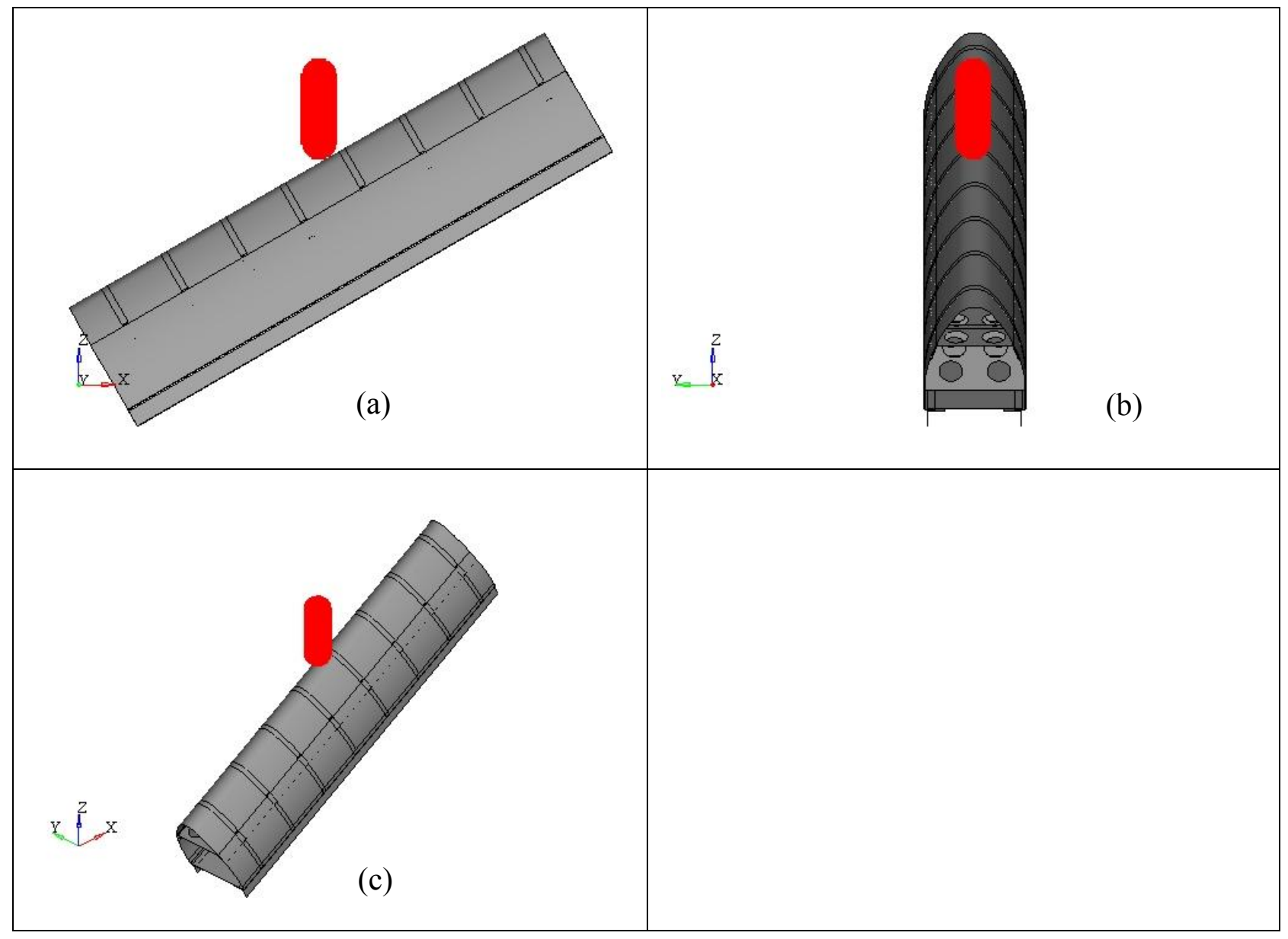

Figure 5.7 Different views of setup for nose radius $62 \mathrm{~mm}$ 


\subsubsection{Birdstrike with impact velocity of 146 knots.}

Birdstrike is carried out on leading edge of nose radius $62 \mathrm{~mm}$ with an impact velocity 146 knots using a 4-lb bird. In figure 5.8 the bird strike on leading edge at different instants of time is shown.

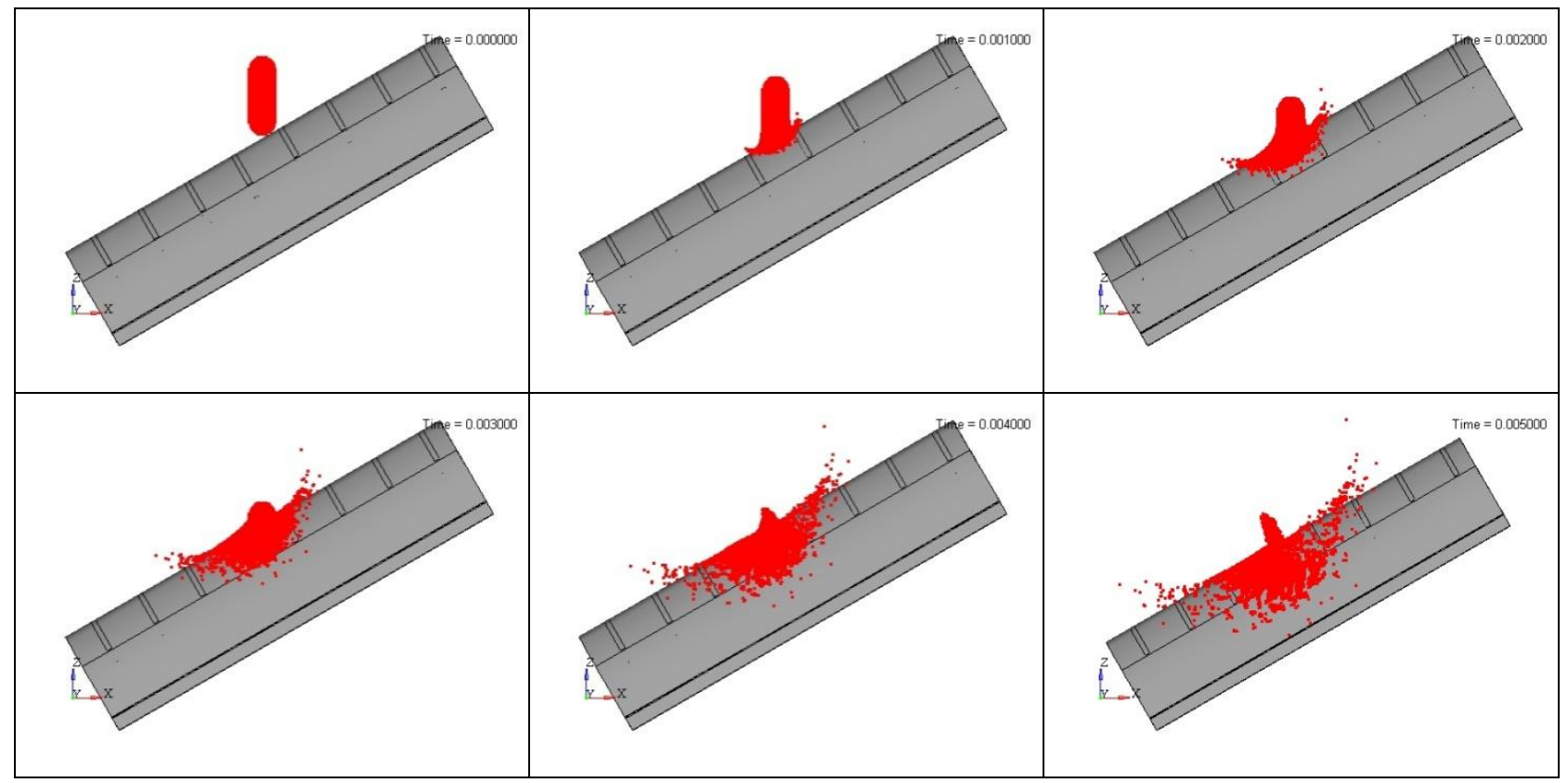

Figure 5.8 Frames at different instants of time at impact velocity 146 knots

In table 5.4 the results of simulation and test data are compared. It can be observed that for both test and simulation there is no damage on leading skin. For diaphragm also the simulation matches the test with no damage on it. And same result is observed in test and simulation for both spar and leading edge ribs with no damage on them. This shows that there is good co relation between testing and simulation results. 
Table 5.4 Comparison of testing and simulation at impact velocity 146 knots

\begin{tabular}{|c||c|c|c|c|c|}
\hline Material & $\begin{array}{c}\text { Velocity } \\
\text { (knots) }\end{array}$ & $\begin{array}{c}\text { Damage on } \\
\text { Leading edge } \\
\text { skin }\end{array}$ & $\begin{array}{c}\text { Damage on } \\
\text { Diaphragm }\end{array}$ & $\begin{array}{c}\text { Damage on } \\
\text { Spar }\end{array}$ & $\begin{array}{c}\text { Damage on Leading } \\
\text { edge ribs }\end{array}$ \\
\hline Test & 146 & None & None & None & None \\
$2014-T 6$ & 146 & None & None & None & None \\
\hline $\begin{array}{c}\text { Simulation } \\
\text { 2014-T6 }\end{array}$ & & & & \\
\hline
\end{tabular}

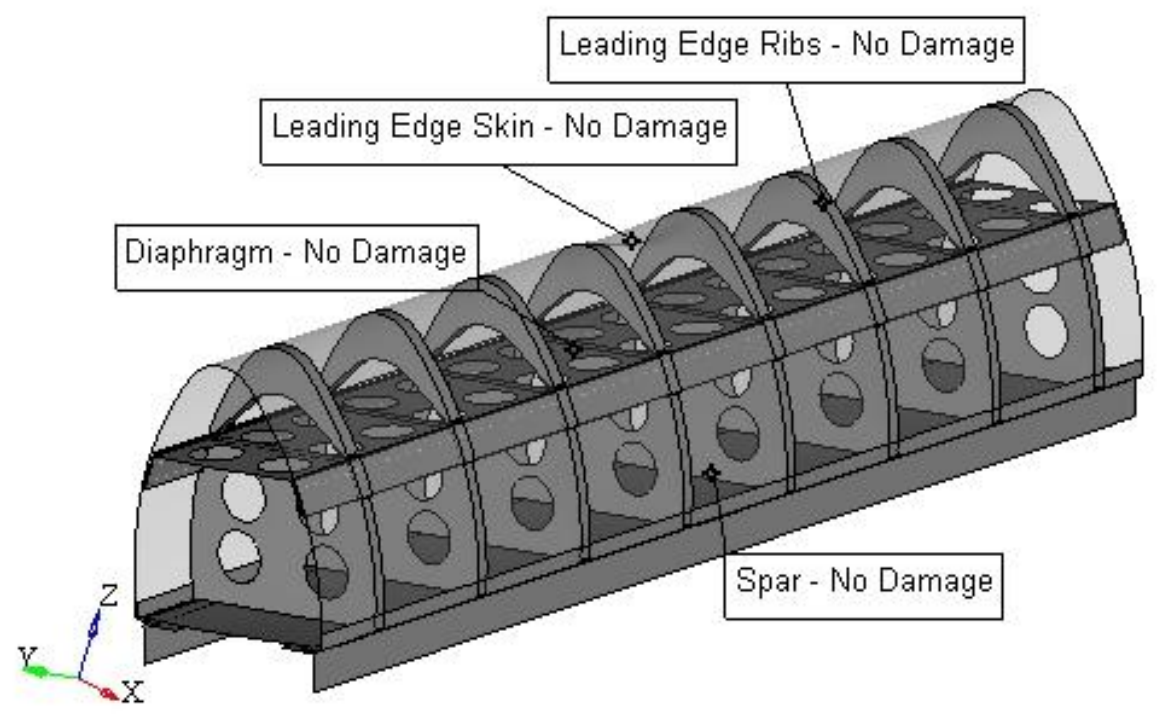

Figure 5.9 Leading edge of $62 \mathrm{~mm}$ nose radius

In figure 5.9 the leading edge structure at the end of the simulation is shown where we can observe the physical condition of different parts of leading edge like leading edge skin, leading edge ribs, spar and diaphragm with no damage on any them which matches with the results from test. 


\subsubsection{Birdstrike with impact velocity of 294 knots.}

The birdstrike is carried out on leading edge of nose radius $62 \mathrm{~mm}$ at an impact velocity of 294 knots using 4-lb bird. In figure 5.10, the bird strike on leading edge at different instants of time is shown.

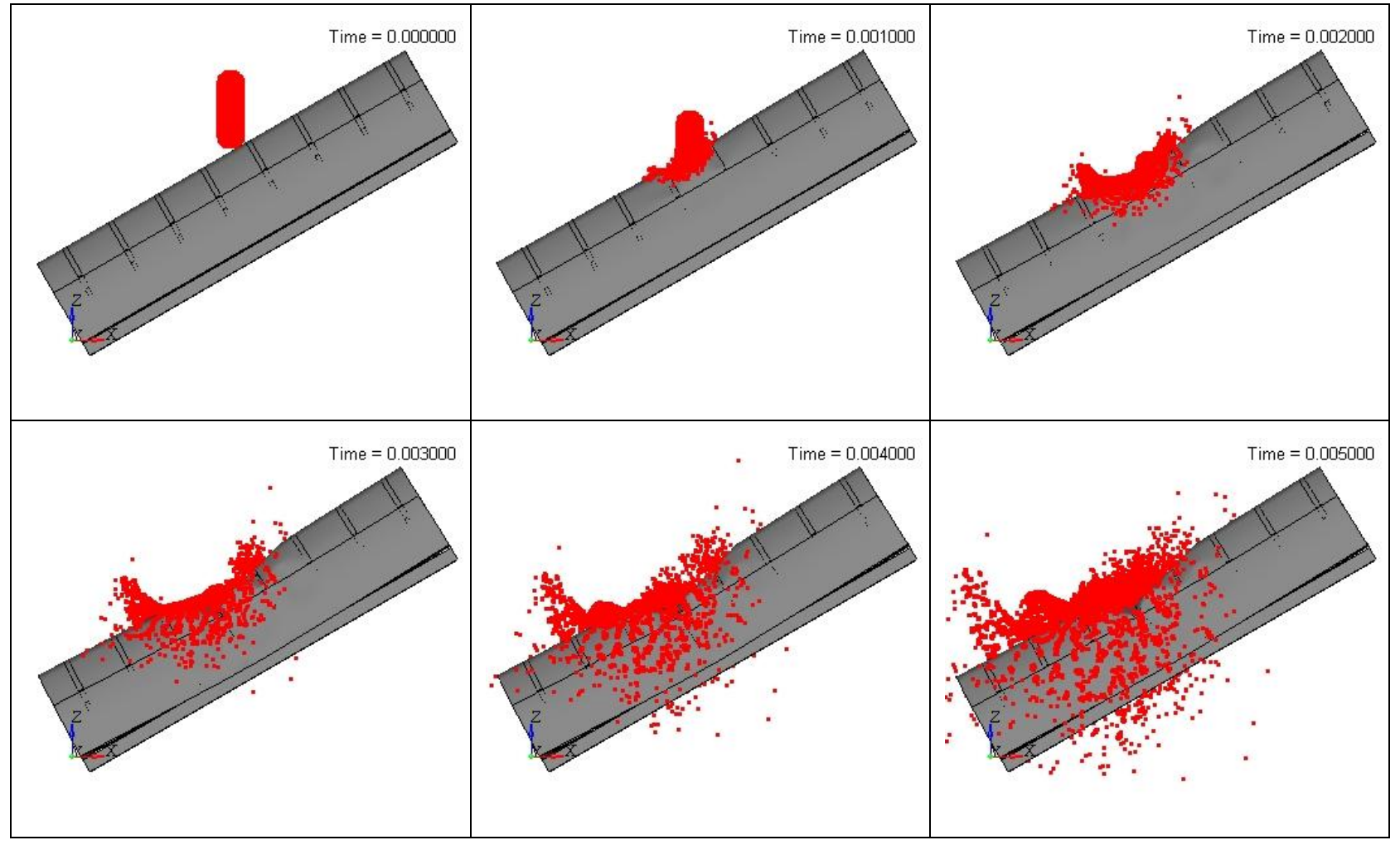

Figure 5.10 Frames at different instants of time at impact velocity 294 knots

In table 5.5 the results of simulation are compared with test data. It can be observed that leading edge is torn along rivet line in simulation which is same as test data. In case of diaphragm the two bays are torn according to test but in simulation two bays are dented. For spar one bay is torn in test and in simulation three bays are dented. For leading edge ribs, there is one torn off and one dented in test and in simulation two are torn-off. There is reasonable co-relation between test and simulation results. 
Table 5.5 Comparison of testing and simulation at impact velocity 146 knots

\begin{tabular}{|c|c|c|c|c|c|}
\hline Material & $\begin{array}{l}\text { Velocity } \\
\text { (knots) }\end{array}$ & $\begin{array}{l}\text { Damage on } \\
\text { Leading edge } \\
\text { skin }\end{array}$ & $\begin{array}{l}\text { Damage on } \\
\text { Diaphragm }\end{array}$ & $\begin{array}{l}\text { Damage on } \\
\text { Spar }\end{array}$ & $\begin{array}{c}\text { Damage on Leading } \\
\text { edge ribs }\end{array}$ \\
\hline $\begin{array}{c}\text { Test } \\
\text { 2014-T6 }\end{array}$ & 294 & $\begin{array}{l}\text { Torn Along } \\
\text { Rivet Line }\end{array}$ & 2 bays torn & 1 bay torn & $\begin{array}{l}1 \text { torn off } \\
1 \text { dented }\end{array}$ \\
\hline $\begin{array}{l}\text { Simulation } \\
2014-T 6\end{array}$ & 294 & $\begin{array}{l}\text { Torn Along } \\
\text { Rivet Line }\end{array}$ & $\begin{array}{l}2 \text { bays } \\
\text { dented }\end{array}$ & 3 bays dented & 2 torn off \\
\hline
\end{tabular}

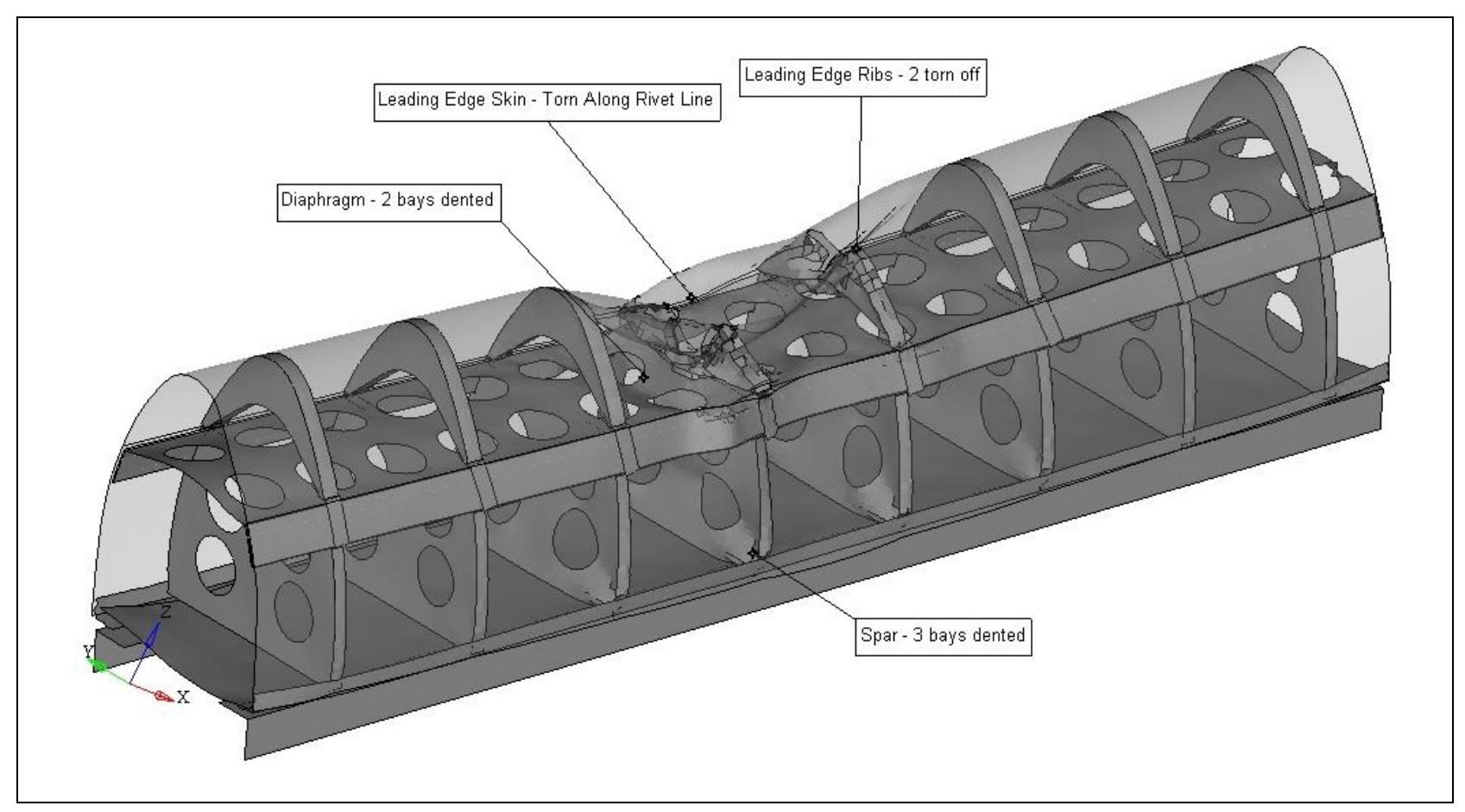

Figure 5.11 Leading edge of $62 \mathrm{~mm}$ nose radius 
In figure 5.11 the leading edge structure at the end of simulation which shows the physical condition of leading edge ribs, leading edge skin, diaphragm and spar.

\subsection{Birdstrike on leading edge of nose radius $64 \mathrm{~mm}$.}

A 4-lb bird of pitch $4 \mathrm{~mm}$ is impacted with velocity of 341 knots and 370 knots on the leading edge of nose radius $64 \mathrm{~mm}$ and results are analyzed by comparing it with the results from test data. The birdstrike set up is shown in different views in figure 5.12 where figure 5.12 (a) shows the front view of the set-up and figure 5.12 (b) and figure 5.12 (c) shows the top view and profile view of set-up respectively.

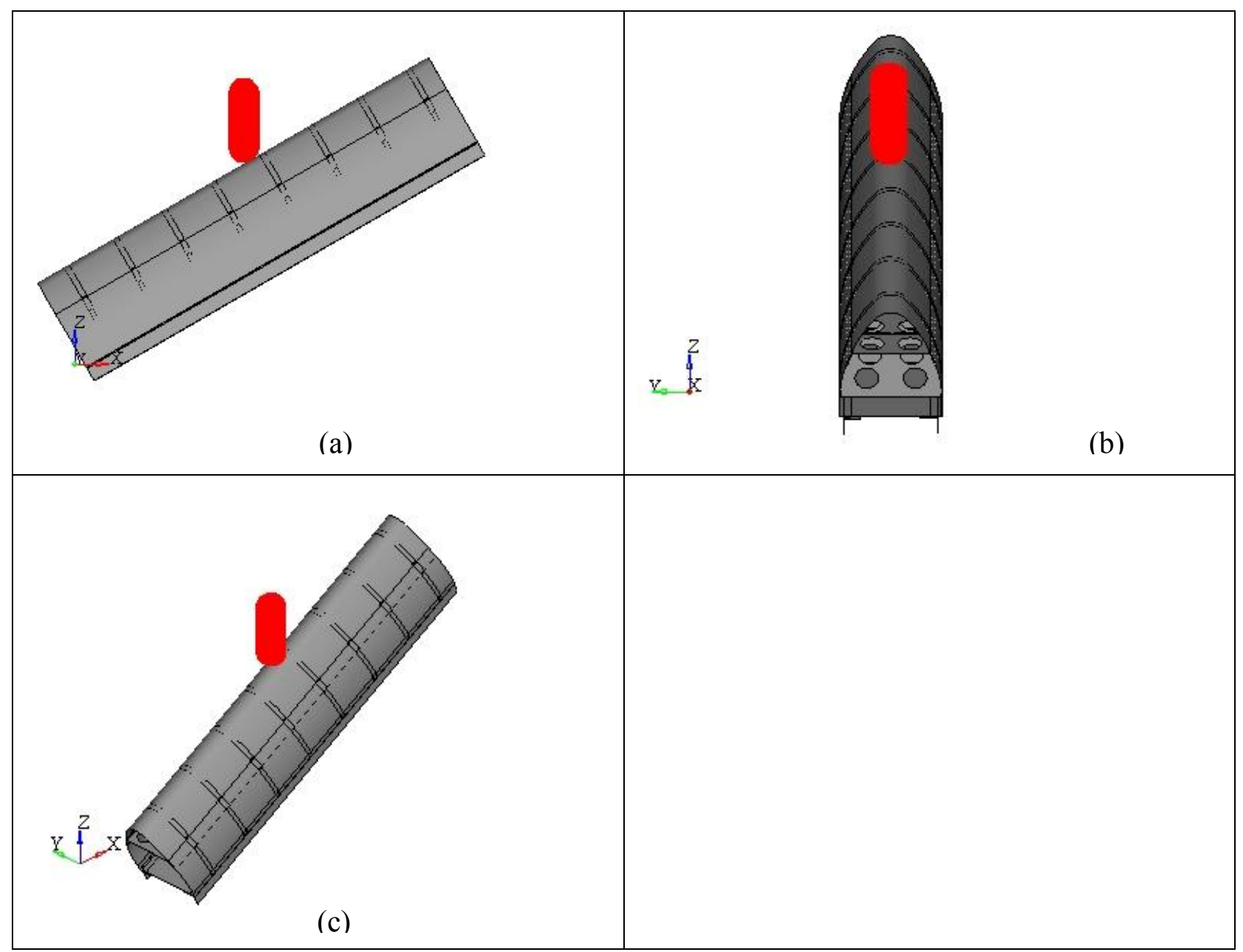

Figure 5.12 Different views of setup for nose radius $64 \mathrm{~mm}$ 


\subsubsection{Birdstrike with impact velocity of 341 knots.}

The birdstrike is carried out on leading edge of nose radius $64 \mathrm{~mm}$ at an impact velocity of 341 knots with bird mass of 4-lb. In figure 5.13, the bird strike leading edge at different instants of time is shown.

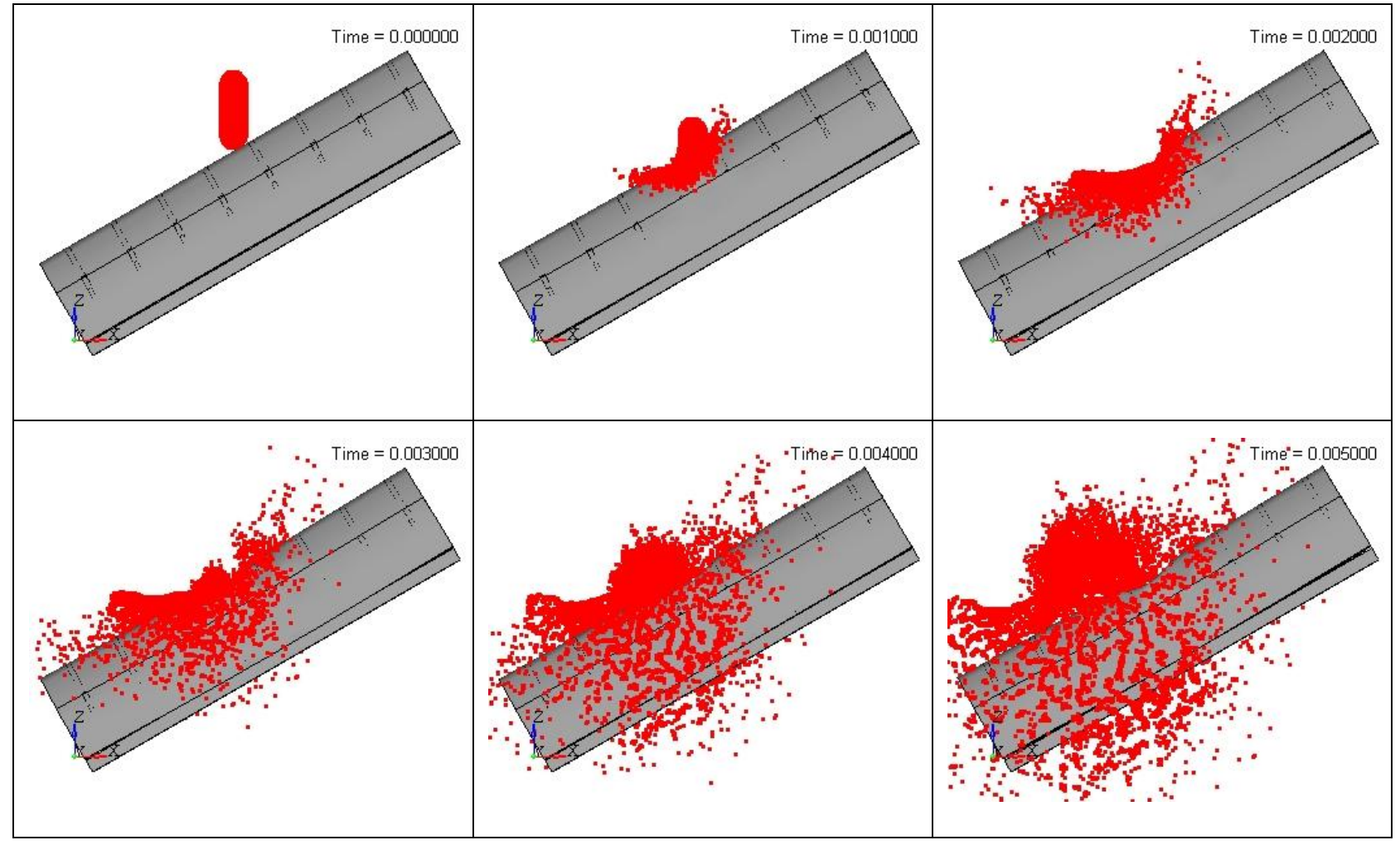

Figure 5.13 Frames at different instants of time at impact velocity 341 knots

In table 5.6 the comparison between testing and simulation is shown. It can be observed that leading edge is dented in simulation which corresponds with test data. For diaphragm, three bays are buckled in test and in simulation two bays are buckled. There is no damage observed on spar in simulation which matches the test. In case of leading edge ribs, there are five buckled in test and we observe two buckled in our simulation. Thus there is reasonable co-relation between test data and simulation results. 
Table 5.6 Comparison of testing and simulation at impact velocity 341 knots

\begin{tabular}{|c|c|c|c|c|c|}
\hline Material & $\begin{array}{l}\text { Velocity } \\
\text { (knots) }\end{array}$ & $\begin{array}{l}\text { Damage on } \\
\text { Leading edge } \\
\text { skin }\end{array}$ & $\begin{array}{l}\text { Damage on } \\
\text { Diaphragm }\end{array}$ & $\begin{array}{l}\text { Damage on } \\
\text { Spar }\end{array}$ & $\begin{array}{c}\text { Damage on Leading } \\
\text { edge ribs }\end{array}$ \\
\hline $\begin{array}{c}\text { Test } \\
\text { 2014-T6 }\end{array}$ & 341 & Dented & $\begin{array}{l}3 \text { bays } \\
\text { buckled }\end{array}$ & None & 5 buckled \\
\hline $\begin{array}{l}\text { Simulation } \\
2014-T 6\end{array}$ & 341 & Dented & $\begin{array}{l}2 \text { bays } \\
\text { buckled }\end{array}$ & None & 2 buckled \\
\hline
\end{tabular}

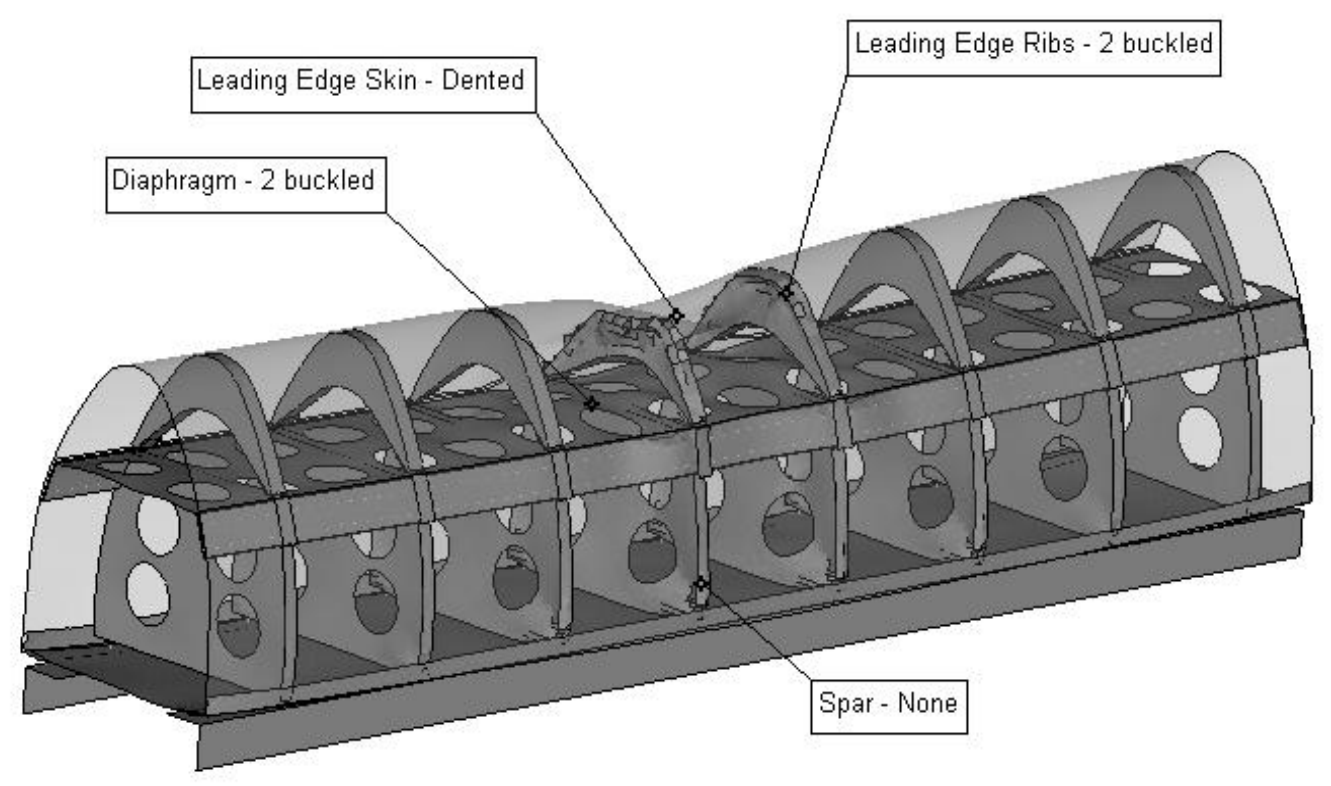

Figure 5.14 Leading edge of $64 \mathrm{~mm}$ nose radius

Figure 5.14 shows the leading edge structure at the end of simulation where the physical damage on leading edge skin, leading edge ribs, spar and diaphragm are observed. 


\subsubsection{Birdstrike with impact velocity of 370 knots.}

The birdstrike is carried out on leading edge of nose radius $64 \mathrm{~mm}$ at an impact velocity of 370 knots with bird mass of 4-1b. In figure 5.15, the bird strike on leading edge at different instants of time is shown.

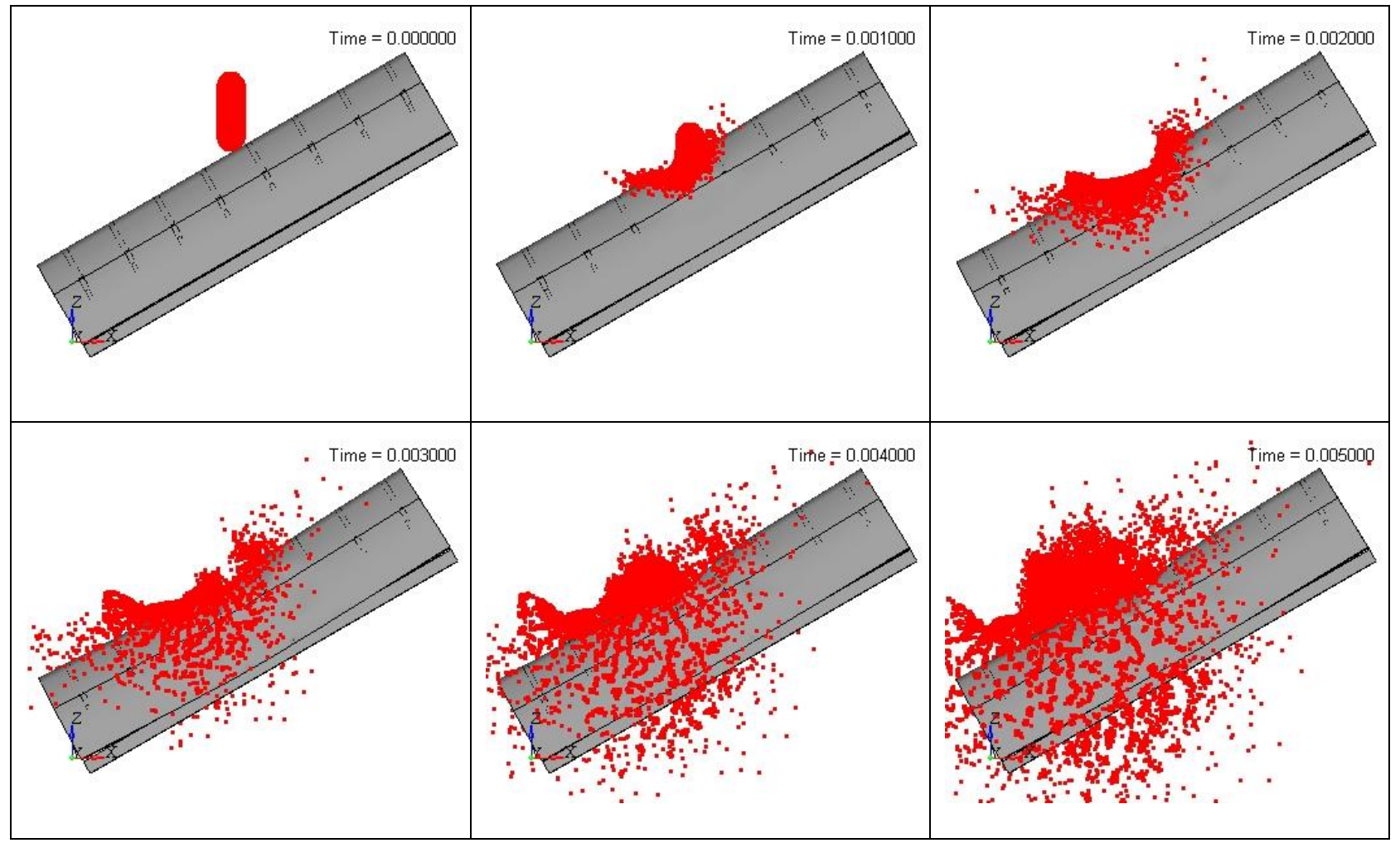

Figure 5.15 Frames at different instants of time at impact velocity of 370 knots

In table 5.7 the comparison between test and simulation results are shown. It can be observed that leading edge skin is torn along rivet for test and in simulation it is dented along rivet line. For diaphragm, two bays are torn-off in test and in simulation also two bays are dented. In case of spar one bay is torn-off and in simulation four bays are dented. At leading edge ribs two are torn-off and one is buckled but in simulation one is torn-off and one is buckled. 
Table 5.7 Comparison of testing and simulation at impact velocity 370 knots

\begin{tabular}{|c||c|c|c||c||c|}
\hline Material & $\begin{array}{c}\text { Velocity } \\
\text { (knots) }\end{array}$ & $\begin{array}{c}\text { Damage on } \\
\text { Leading edge } \\
\text { skin }\end{array}$ & $\begin{array}{c}\text { Damage on } \\
\text { Diaphragm }\end{array}$ & $\begin{array}{c}\text { Damage on } \\
\text { Spar }\end{array}$ & $\begin{array}{c}\text { Damage on Leading } \\
\text { edge ribs }\end{array}$ \\
\hline Test & 370 & $\begin{array}{c}\text { Torn Along } \\
\text { Rivet Line }\end{array}$ & $\begin{array}{c}2 \text { bays torn } \\
\text { off }\end{array}$ & 1 bay torn & 2 torn off \\
1 buckled
\end{tabular}

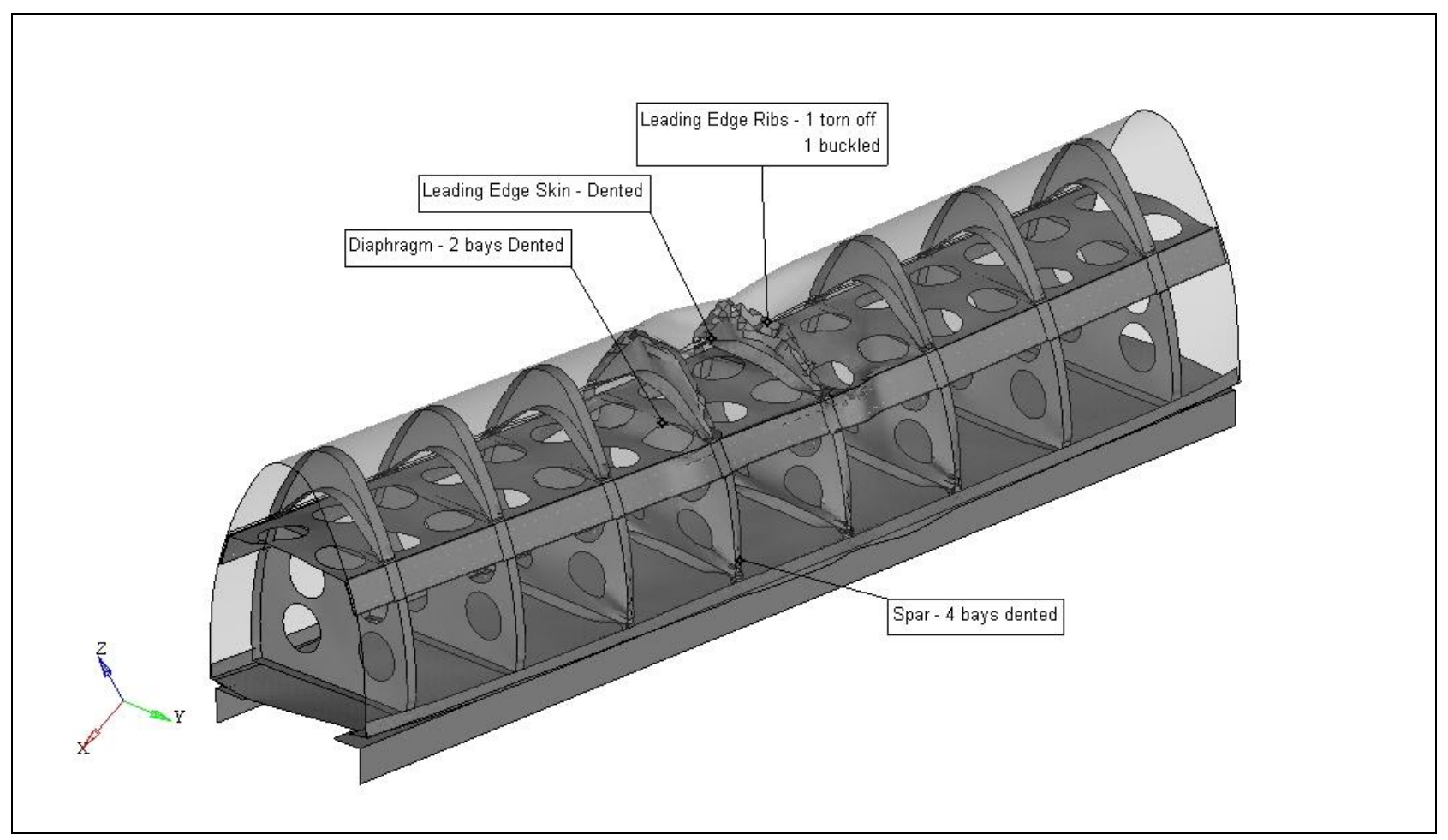

Figure 5.16 Leading edge of $64 \mathrm{~mm}$ nose radius

Figure 5.16 shows the physical condition of leading edge structure at the end of simulation which shows the damage on leading edge skin, leading edge ribs, spar and diaphragm. 


\section{CHAPTER 6}

\section{CONCLUSION AND RECOMMENDATION}

\subsection{Conclusions}

The objective of the study was to devolop a methodology to certify an aircraft for birdstrike by analysis technique. To achieve this objective, the bird is modeled using Smooth Particle Hydrodynamics (SPH) and is validated by two different approaches.

In the first case, SPH bird model is impacted on aluminum target. The bird is impacted on to the target at different impact velocities for different thicknesses of plate. The results obtained are compared with the data obtained from the tests carried out by Cessna [15].The comparison of results between $\mathrm{SPH}$, lagrangian and test results for 0.25 " and 0.16 " are in reasonable correlation. The variation in test and simulation results is around $12 \%$.In case of 0.10 " thick panel, material failure is observed which represents the actual test scenario.SPH technique for bird model is found to be an efficient technique because of minimum computation time.

In case of second validation of SPH bird model with steel target, the results obtained from the simulation are compared with test data from literature [1].The results like peak force, impulse are obtained from the simulation and by carrying out certain mathematical operations, the results are plotted with test data. All the plots show good relation with test results and thus the bird model is validated. The effect of pitch distance is observed by varying the bird pitch by $4 \mathrm{~mm}$ and $10 \mathrm{~mm}$, the results show not much variation and hence can be concluded that for Birdstrike analysis the effect of pitch distance between SPH particles is negligible.

The validated SPH bird model is impacted on to the leading edge of aircraft wing. The leading edge is modeled in CATIA V5 and dimensions are obtained from Royal Aircraft Establishment report [20]. All connections and material properties are defined in Altair Hypermesh 9.0.The connections between different parts of Leading Edge is defined using beams and spotwelds.

The leading edge is modeled for three different dimensions of nose radius viz $12.7 \mathrm{~mm}$, $62 \mathrm{~mm}$ and $64 \mathrm{~mm}$ and impacted at velocities ranging from 250 to 370 knots. The results obtained 
are compared with the test data. The comparison shows reasonable correlation between the testing and simulation.

It can be concluded the certification of aircraft by analysis technique saves time, money and most importantly standardizes the method of certification.

\subsection{Recommendations}

As a part of future work, the effect of static and dynamic friction on the analysis can be observed. By varying the values of static and dynamic friction from 0.1 to 0.9 , there might be variation in the simulation results.

The bird model can be improved by studying the effect of Equation of State. By studying EOS, the composition of the bird can be understood. For instance there will variation in the values of $E$ and $C_{v}$ (LS Dyna deck) if composition of bird which is $90 \%$ water and $10 \%$ air is varied.

The effect of different shapes of bird can be observed. For example if the bird is modeled in rectangular shaped or cylindrical shape with single spherical end. The bird can also be modeled by having a bony structure inside and analyzing if there are any variations in results.

In this study the bird model is impacted on aluminum and results are compared with test data. As a part of future work, the behavior of the bird model when impacted on a composite structure can be studied and its correlation with test data can be analyzed.

Birdstrike analysis can be carried out on different parts of airplane like engine, fuselage parts, windshield and other external airframe structures and results can be analyzed. 
REFERENCES 


\section{LIST OF REFERENCES}

[1] J.P Barber, H.P Taylor, J.S Wilbeck, Bird Impact Forces and Pressures on Rigid and Compliant Targets, Air Force Flight Dynamics Laboratory Technical Report, 1978

[2] A publication of shock and vibration information center, U.S. Naval Research Laboratory, Washington D.C: The Shock and Vibration bulletin, 1978.

[3] http://www.ntsb.gov/events/2009/Oklahoma-CityOK/2_web_bird_strike_cert_and_damage_john_ocallaghan.pdf, (Cited 2009)

[ 4 ] S. Sarva, A.D Mulliken, M.C Boyce, Mechanics of Transparent Polymeric Material Assemblies Under Projectile Impact, Massachusetts Institute of Technology, Dept. Mechanical Engineering Institute for Soldier Nanotechnologies, 2004

[ 5 ] C.H Edge, J. Degrieck, Derivation of a Dummy Bird for Analysis and Test of Airframe Structures ,Farnborough Aerospace Centre, Hampshire, UK, and Department of Applied Mechanics, University of Gent, Belgium, Technical Paper, 1999

[6] R. Budgey, The Development Of A Substitute Artificial Bird By the International Birdstrike Research Group for Use In Aircraft Component Testing Birdstrike Avoidance Team, Central Science Laboratory, 2000.

[ 7 ] Federal Aviation Administration http://rgl.faa.gov/ (Cited 2009)

[ 8 ] Standard Test Method for Bird Impact Testing of Aerospace transparent Enclosures, ASTM International F-330-89, 2004

[ 9 ] D. R. Lesuer, Experimental Investigations of Material Models for Ti-6Al-4V Titanium and 2024-T3 Aluminum U.S. Department of Transportation (Federal Aviation Administration), 2000

[10] P. Barber, Characterization of bird impacts on a rigid plate, University of Dayton Research Institute and Air Force Materials Laboratory, 1975

[11] http://i.usatoday.net (Cited 2009)

[ 12 ] G. Kay, Failure Modeling of Titanium 6Al-4V and Aluminum 2024-T3 With the JohnsonCook Material Model, Federal Aviation Administration Report DOT/FAA/AR-03/57, 2003 
[13 ] M.Hormann, U.Stelzmann, M.A.McCarthy, J.R Xiao, Horizontal Tail plane Subjected to Impact Loading CAD-FEM GmbH Grafing/Munich, and Dept. of Aeronautical and Mechanical Engineering University of Limerick Ireland, and Center for Composites Materials University of Delaware Newark

[ 14 ] M Anghileri, L M L Castellleti, V. Mazza, Approaches to the Analysis of Impacts with Penetration, Dept. Aerospace Engineering, Politecnico di Milano Italy, 2005.

[15] R. D Furtado, Finite Element Analysis of Birdstrike on Aircraft Structures, Department of Mechanical Engineering, Wichita State University, 2000.

[16 ] M.H. van Houten and H. Kaplan, Towards a novel design method for impact on leading edges, National Aerospace Laboratory, Department AVCE, Netherlands and Department of Mechanical Engineering, Applied Mechanics, University of Twente, Netherlands.

[17 ] C. Shultz, Birdstrike Simulation Using ANSYS LS/DYNA, Phoenix Analysis and Design Technologies, Inc.

[ 18 ] National Aerospace Laboratory, Technical report: Design and Testing of a Composite Birdstrike resistant leading edge, SAMPE Europe Conference \& Exhibition, Paris, France, April 2003.

[ 19] C A H Ortecho, Robust Birdstrike Modeling using Ls Dyna, University of Puerto Rico, 2006.

[20 ] I.I McNaughtan, The design of leading-edge and intake wall structure to resist bird impact, Royal Aircraft Establishment, 1972.

[21 ] “LS Dyna User manual V971” LSTC.

[ 22 ] Altair Hypermesh user manuals.

[23 ] Primer user manuals.

[24 ] Research Paper, The Hazard Posed to Aircraft by Birds, Australian Transport Safety Bureau, 2002.

[25] Understanding and reducing bird and other wildlife hazards to Aircrafts, Bird Strike Committee USA, 2009

[26] Material Property Data, Matweb.com (Cited 2009)

[ 27 ] http://www.knovel.com/web/portal/browse/display?_EXT_KNOVEL_DISPLAY_bookid $=754$, (Cited 2009) 
